\title{
Evaluation of the OSHA Local Emphasis Program (LEP) for Logging in West Virginia
}

\author{
Olukemi O. Alonge \\ West Virginia University
}

Follow this and additional works at: https://researchrepository.wvu.edu/etd

\section{Recommended Citation}

Alonge, Olukemi O., "Evaluation of the OSHA Local Emphasis Program (LEP) for Logging in West Virginia" (2013). Graduate Theses, Dissertations, and Problem Reports. 4945.

https://researchrepository.wvu.edu/etd/4945

This Thesis is protected by copyright and/or related rights. It has been brought to you by the The Research Repository @ WVU with permission from the rights-holder(s). You are free to use this Thesis in any way that is permitted by the copyright and related rights legislation that applies to your use. For other uses you must obtain permission from the rights-holder(s) directly, unless additional rights are indicated by a Creative Commons license in the record and/ or on the work itself. This Thesis has been accepted for inclusion in WVU Graduate Theses, Dissertations, and Problem Reports collection by an authorized administrator of The Research Repository @ WVU. For more information, please contact researchrepository@mail.wvu.edu. 
Evaluation of the OSHA Local Emphasis Program (LEP) for Logging in West Virginia

\author{
Olukemi O. Alonge
}

Thesis submitted to the Benjamin Statler College of

Engineering and Mineral Resources

West Virginia University

In Partial Fulfilment of the Requirements

for the degree of

Master of Science

in

Safety Management

Gary L. Winn, PhD., Committee Chair

Michael J.Klishis, Ph.D

Xiaopeng Ning, Ph.D

Safety Management Program

Department of Industrial and Management Systems Engineering Benjamin Statler College of Engineering and Mineral Resources

Morgantown, West Virginia

2013

Keywords: Logging Safety, Logging Industry, West Virginia Division of Forestry, Local Enforcement Programs 


\section{ABSTRACT \\ Evaluation of the OSHA Local Emphasis Program (LEP) for Logging in West Virginia}

\section{Olukemi O. Alonge}

This research aimed at an improved method for evaluating the West Virginia Occupational Safety and Health Administration's Local Emphasis Program (WV OSHA LEP) for Logging in West Virginia. The LEP currently uses for assessment: loggers' training, inspections at logging sites, number of fatalities and 75\% of loggers' participation to determine the program's effectiveness annually. The research here proposes the use of a larger data capture to evaluate the impact of the LEP on loggers' safety.

A heuristic method using the Iceberg model of safety was applied to assess loggers' safety based on the desired safety outcome measures outlined in the OSHA directive 2012-11(CPL 04). In this context, loggers' safety is understood and better assessed when fatalities and other safety related incidents or costs such as injuries, near misses, unsafe acts and conditions, days lost or transferred from job, healthcare costs and workers' compensation claims are tracked and monitored. This new predictive model identifies that minor and non-fatal incidents play a role in predicting major incidents and fatalities thus allowing the use of more appropriate safety indicators to determine the success of the program.

A quantitative research method was used to accumulate and sort data relating to loggers' training, operations, inspections, fatalities, violations and loss data in West Virginia. Based on ten years of records kept by WV OSHA, West Virginia Division of Forestry (WV DOF) and West Virginia Insurance Commission (WV IC), a bi-variate regression analysis was used to determine the best fit model that predicted an association between the program's inputs (independent variables X: Training and Inspections) and any combination of expected or desired safety outcomes (dependent variables Y: fatality rates, violations and medical costs) with the aid of Microsoft Excel, Minitab and SAS computer programs.

The resulting statistics and fit charts revealed that, the model of association between the rates of planned inspections and rates of medical costs of logging injuries has the best fit with correlation ' $r$ ' $=-0.88$, $\mathrm{R}^{2}$ (adj) $=78.9 \%$ and $\mathrm{P}$ value $=0.044$ indicating significance. Other good fit models of association with the rate of inspections were rates of violations, cost of violations and rates of unplanned inspections (due to complaints and accidents). Therefore, the research suggests that the rates of medical costs of logging injuries, serious and repeat violations, cost of violations and unplanned inspections be considered as better measures of severity and unsafe acts/conditions to track the success of the LEP during its evaluation.

Based on research findings, it was concluded that though the current evaluation method helps WV OSHA to meet the guidelines of the Federal OSHA strategic goal for LEPs, it does little to measure the impact of the program on the safety of workers in the West Virginia logging industry. 


\section{ACKNOWLEDGEMENTS}

I like to thank all my instructors in WVU Safety Management program for the knowledge they have given me so far which provided me the foundation on which this research was conducted.

My sincere appreciation goes to the staff of the West Virginia Insurance Commission, West Virginia Division of Forestry and West Virginia Occupational Safety and Health Administration offices in Charleston and Pittsburg for giving out necessary information and data to support the study.

I am thankful to the staff of National Institute of Occupational Safety and Health (NIOSH): Dr. Jennifer Bell and Dr. Elyce Biddle whom with their wealth of experience guided and advised me through the study to achieve success

I like to thank Dr. Gerry Hobbs who took out time to explain to me the statistical analysis required for this research.

Special thanks to Dr. Ben Spong of the Appalachian Hardwood Center of West Virginia University for his guidance on utilizing the study data for meaningful interpretations.

I am grateful to Dr. Michael Klishis, the coordinator of the safety graduate program and Dr. Xiaoping Ning who served on the thesis committee for their support, guidance and advice throughout the course of the study.

I greatly acknowledge and appreciate Dr. Gary Winn who served as my advisor and committee chairman for his support and guidance throughout the entire development of the study and my graduate program.

Finally I would like to say a big thank you to my family for their love and encouragement, for their moral and financial support throughout my study. 


\section{TABLE OF CONTENTS}

Title Page

Abstract

ii

Acknowledgement iii

Table of Contents $\quad$ iv

List of Abbreviations $\quad$ v

List of Figures $\quad$ vi

List of Tables $\quad$ vii

$\begin{array}{ll}\text { 1.0 INTRODUCTION } & 1\end{array}$

1.1 Background 1

1.2 Research Objectives 4

1.3 Scope of Research 4

1.4 Problem Statement 5

2.0 LITERATURE REVIEW

2.1 Logging in West Virginia 6

2.2 Logging and Safety So Far 6

$\begin{array}{lll}2.3 & \text { Past Safety Efforts and Interventions } & 10\end{array}$

2.3.1 Criteria for Recommended Standard (NIOSH) 10

2.3.2 OSHA Logging Standards 11

2.3.3 Certified Logger Program 11

2.3.4 Loggers Safety Initiative 11

$\begin{array}{lll}2.3 .5 & \text { OSHA Enforcement } & 12\end{array}$

2.3.5.1 Emphasis Programs 13

2.4 Local Emphasis Program (LEP) for Logging in West Virginia 13

$\begin{array}{ll}\text { 2.4.1 Evaluation of the Current LEP } & 14\end{array}$

2.5 The Safety Iceberg Theory 16

$\begin{array}{lll}2.6 & \text { Summary and Criticism } & 17\end{array}$ 
3.0 RESEARCH DESIGN AND METHODS 19

3.1 Research Design 19

3.2 Data Collection 20

$\begin{array}{lll}3.3 & \text { Statistical Methods } & 20\end{array}$

3.4 Data Analysis 23

3.5 Data Presentation 23

4.0 DATA PRESENTATION AND RESULTS 29

4.1 Tests and Results 29

4.2 Discussion of Results 30

4.3 Study Limitations 32

5.0 CONCLUSIONS AND RECOMMENDATIONS 34

5.1 Conclusion 34

$\begin{array}{lll}5.3 & \text { Recommendations } & 35\end{array}$

$\begin{array}{lc}\text { REFERENCES } & 38\end{array}$

$\begin{array}{lr}\text { APPENDICES } & \mathbf{4 0}\end{array}$

Appendix A Sample: Logging Inspection Database 40

Appendix B Sample Inspection Summary 41

Appendix C Sample Inspection and Incident Investigation Summary 42

Appendix D Derived Variables 43

Appendix E JMP SAS Data Analysis Reports 45

Appendix F Minitab Analysis Reports 58

Appendix G OSHA Directive 2012-11 (CPL 04) Logging in West Virginia 63

Appendix H Procedures for Approval of Local Emphasis Programs LEP 66 


\section{LIST OF ABBREVIATIONS}

$\begin{array}{ll}\text { BMP } & \text { Best Management Practices } \\ \text { BLS } & \text { Bureau of Labour Statistics } \\ \text { CPR } & \text { Cardiopulmonary Resuscitation } \\ \text { CSHO } & \text { Certified Safety and Health Officers } \\ \text { DART } & \text { Days Away Restricted/Transferred from Work } \\ \text { EMS } & \text { Emergency Medical Services } \\ \text { FACE } & \text { Fatality Assessment and Control Evaluation } \\ \text { FIRM } & \text { Field Inspection Reference Manual } \\ \text { IMIS } & \text { Integrated Management Information System } \\ \text { LEP } & \text { Local Enforcement Program } \\ \text { LSI } & \text { Loggers Safety Initiative } \\ \text { MHST } & \text { Miners' Health, Safety and Training } \\ \text { NAICS } & \text { North American Industry Classification System } \\ \text { NEP } & \text { National Emphasis Programs } \\ \text { NIOSH } & \text { National Institute of Occupational Safety and Health } \\ \text { OSHA } & \text { Occupational Safety and Health Administration } \\ \text { RSOL } & \text { Regional Solicitor of Labor } \\ \text { WC } & \text { Workers' Compensation Claims } \\ \text { WV } & \text { West Virginia } \\ \text { WV IB } & \text { West Virginia Insurance Board } \\ \text { WV IC } & \text { West Virginia Insurance Commission } \\ \text { WV DOF } & \text { West Virginia Division of Forestry } \\ \text { WV FA } & \text { West Virginia Forestry Association } \\ \text { WV WCB } & \text { West Virginia Workers' Compensation Board } \\ \text { WVU } & \text { West Virginia University } \\ \end{array}$




\section{LIST OF FIGURES}

Figure 1

Logging Areas 


\section{LIST OF TABLES}

Table 1 Timber license holders and Notifications for Logging Operations that were received by WV DOF in West Virginia over the years

Table 2 Loggers Trained and Certified in the WV DOF Certified Loggers Training Program over the Years

Table 3 OSHA inspections at logging sites, violations and fatalities recorded over the years

Table 4 Loss data for NCCI classes $2702 \& 2709$

Table 5 Results of Statistical Analysis 


\section{CHAPTER 1: INTRODUCTION}

\subsection{Background}

According to the U.S Department of Labour, (BLS 2011, 2013), logging remains one of the most hazardous occupations in the nation with the second highest fatality rates of 102.4 per 100 , 000 workers and 104 per 125 million hours worked. Logging comes after fishing which occupies the first position with fatality rates of 121.2 per 100,000 workers and 127.3 per 66 million hours worked.

In 2011, a total of 65 fatal injuries were recorded for the logging occupation nationwide (BLS 2013). Three of these injuries were recorded in West Virginia where the injury rates associated with logging have been among the highest in the nation. In the past, most registered logging businesses in the state of West Virginia had high incident rates and experience modifier rates greater than one which resulted in very high workers compensation rates for the industry in 1999 ( Carolee, 2001)

Most logging incidents have involved employees being crushed by falling trees, falling rocks and mishaps with heavy equipment such as bulldozers, forklifts, skidders, chainsaws and truck accidents leading to injuries and death of employees in some cases. These causes of fatal and non-fatal injuries usually associated with operations at logging sites continuously attracts the attention of the Occupational Safety and Health Administration (OSHA) and other stakeholders of the logging industry to loggers' performances during logging operations.

The West Virginia Forestry Association (WV FA), West Virginia Division of Forestry (WV DOF) and West Virginia Occupational Safety and Health (WV OSHA) began in 1999 some collaborative efforts with the state's Workers Compensation Board (WCB) to promote programs which would improve loggers' safety in the state. The combined efforts of these organizations led to the development of the Loggers' Safety Initiative (LSI) program which had the goal of reducing the frequency and severity of logging-related accidents (Carolee, 2001). 
Before that time, only a few companies had formal or structured safety program and logging safety was not really emphasized. Loggers carried out logging operations without much safety information being utilized. At that time, WV FA made some efforts to train loggers in order to improve logging safety even though it did not necessarily make much improvement on the high workers compensation rates; no formal assessments could be located.

The collaborative effort of the government agencies created an avenue for WV OSHA to initiate its outreach and inspection activities for loggers' safety in the state. The LSI was implemented in the state for four years from 1999 to 2002. Following the LSI program, a Local Emphasis Program (LEP) has been conducted by WV OSHA in a continuous effort to mitigate the problems relating to the safety of loggers.

Although these two programs (LSI and LEP) were concluded by program administrators to have improved loggers' safety through training, intensified inspections and incentives given to employers in the state, some studies oppose this view. A NIOSH 2002 investigation revealed that high injury rates and workers' compensation (WC) claims persisted even in companies that participated in the LSI training program. WV OSHA, despite arguments on the effectiveness of the training program on loggers' safety, continues to implement LEP and evaluate the effectiveness of the program using the observed program activities and its small clusters of parameters as criteria to determine its success on an annual basis. Currently, the LEP uses only inspection data, number of fatalities and seventy five percentage of loggers' participation to determine the program's effectiveness and get approval for implementation in the next year. Although the importance of this step (LEP evaluation) cannot be overemphasized in its usefulness to manage and continuously improve the program, less is known about its actual effectiveness in measuring the impact of the LEP as it relates to the entire spectrum of safety for the logging industry and upon behaviors or performances of loggers in particular. 
To address these shortcomings, the current WV LEP evaluation model and criteria will be examined in this research project which will focus on creating an improved predictive model for which loggers' safety can be monitored by the most appropriate safety indicators to determine the success of the LEP. To achieve this, the weak points of the current evaluation method in tracking the safety of loggers will be identified followed by a quantitative research method which will be administered to accumulate, sort and analyse data relating to loggers' employment, operations and safety. These available data will include but not be limited to: training, inspections, fatality rates, incident rates, days away restricted/transferred (DART), violations and number of timber licence holders in West Virginia. Richer models of evaluation that will cover more aspects of loggers' safety conditions in the logging business environment will be identified. It is expected that the resulting analysis will show models with stronger associations between the program input activities and desired safety outcomes and also produce very high coefficient of determination of how much variance in the desired outcomes are produced by the program activities.

Finally, suggestions will be made to WV OSHA about any improved methods through which a better prediction of the program in terms of its effectiveness in impacting loggers' safety in the state might be made in the future, if WV OSHA adopts any of such methods. 


\section{$1.2 \quad$ Research Objectives}

The goal of the research is to consider the group of appropriate indicators for improving loggers' safety assessment, and from that group determine those with strong statistical support. The current research will investigate the association between program activities and outcome measures used in evaluating the LEP. In addition, other measures that might contribute to the safety of loggers and logging business enrolled in the LEP will be examined to ascertain the adequacy of using the current outcome measures. Currently, fatality rates and implementation of a safety program by $75 \%$ of the employers inspected are the benchmarks for assessment in determining the safety of loggers in the state via the LEP.

To achieve the purpose of the research, the following research aims have been identified:

1. To examine the activity and outcome measures which are currently being used to evaluate the WV LEP.

2. To identify the most appropriate and strongest safety indicators for evaluating the effectiveness of the Local Enforcement Program in order of the strength of association that exists between the program elements and desired outcomes.

3. To propose a better predictive model for measuring the effectiveness of the WV LEP based on stronger models of associations identified.

4. To note strengths and weaknesses of available data used in this or any assessment of the LEP.

\subsection{Scope of Research}

The scope of the research will be restricted to examining existing and possible LEP evaluation methods and the scope will be constrained to available data sources. The study will focus on how the success of the program can be measured leading to a richer model for evaluating the effectiveness of the LEP. 
As a result of data quality or data availability, the study may not determine the effectiveness of the LEP or measure its impact in reducing logging incidents. However, given reasonably good-quality data, a quantitative research approach involving regression analysis will be used to examine possible set of relationships that exist between independent LEP variables (Training and Inspections) and its outcome variables with the aid of Minitab and SAS computer programs.

\subsection{Problem Statement}

To determine the LEP's effectiveness on reducing logging hazards and to get federal OSHA's approval to implement program in the next year, the WV LEP currently uses four activity measures (inspections, loggers attending training sessions, number of violations per inspections, number of loggers removed from risk) and two outcome measures (reduction in the number of fatalities and implementation of a safety and health program by at least $75 \%$ of employers inspected). But past studies of programs similar in structure and function to the LEP have shown that fatality and injury claim rates dropped anecdotally as a result of external factors such as mechanization and demographics i.e. age and experience of loggers (Bell, 2002). In other words, it is possible that a single desired outcome such as 'reduction in fatality' responds to other several factors than the one being monitored or applied in any safety program. Therefore, this research questions the adequacy and validity of the current evaluation method in measuring loggers' safety based on actual principles of practising safety. It also questions the association that exist between the observed safety outcomes and current program activities of the LEP to ascertain the success of the LEP in reducing logging hazards. The study aims at identifying an improved method of evaluating and monitoring the safety of loggers within the logging industry. 


\section{CHAPTER 2: LITERATURE REVIEW}

\subsection{Logging in West Virginia}

While logging is often considered to be a very hazardous occupation in the United States (BLS 2011), West Virginia Department of Commerce reports that "West Virginia is the second leading hardwood state in the nation with 22.3 billion cubic feet of hardwood growing stock", it also forms an important component of the wood products industry which significantly contributes to West Virginia's economy through the provision of jobs and forest products to the state and its communities. According to WV DOF, analysis of the state's forests and related natural resources, “the forest products industry contributes over $\$ 4$ billion annually to the state's economy and over $\$ 45$ million in taxes to the state. However this significant contribution that has steadily increased over the last 20 years, a recent economic recession has seriously impacted the growth of the wood products industry and this has subsequently resulted in the hike in prices of timber and decreased logging activities by 30-40 percentages over the last three years (2010-2013). The future of the wood market remains uncertain even though the biomass market's rising interest in the wood market" (WV DOF Forest Resource Assessment Reports, 2010). Currently, there are about 909 loggers and 62 Consulting Foresters and Forestry Technicians in the state (West Virginia Department of Commerce, 2013).

\subsection{Logging and Safety So Far}

According to the National Institute of Occupational Safety and Health (NIOSH), in 2010, the logging industry employed 95,000 workers nationwide, and accounted for 70 deaths. This resulted in a fatality rate of 73.7 deaths per 100,000 workers, a rate that was 21 times higher than the overall industrial fatality rate in the US for that year i.e. 3.4 deaths per 100,000 (NIOSH, 2012). 
Historically, logging has been classified as a high-hazard occupation with several factors that contribute to its hazardous nature in the United States. The new logging process involves two major set of activities, the first set includes operations involving timber harvesting while the second set of activities include transfer of $\log s$ and other raw materials from the forest to various processing industries as furniture, lumber, paper, engineered products, pellet manufactures, bio energy production and landscaping suppliers around the state. Both set of operations involve the use of tools and heavy equipment such as chain saws, skidders, feller bunchers, bulldozers and forklifts which pose hazards to employees. Loggers are required to use these tools and equipment while dealing with heavy weights of falling, rolling and sliding trees and logs which makes it difficult for them to maintain stable footings and good body positioning that will keep them out of line of falling objects while at work. Past studies reveal that "only one percentage of logging fatalities and onefifth of injuries result from chainsaw accidents and almost one-fourth of logging injuries occurred when loggers were hit by trees, limbs or logs while another quarter were caused by slips, trips or falls" ( Holcomb,1995).

The risk of injury and fatality becomes even higher when loggers are exposed to working at remote sites very far from healthcare facilities and on sites with rough terrains and extreme weather conditions such as wind, rain and snows. Also, low levels of awareness of logging safety standards and best practices have been found to contribute to the increasing risks. For a number of significant cases, logging employees working on sites and in sawmills have been found to have suffered injuries as spinal cord damages, amputations and lacerations. According to Myers and Fosbroke, (1994), "most cases that led to the death of loggers were as a result of being struck by an object and the leading body parts injured were the leg, knee, and hip."

In 1995, NIOSH revealed that death cases related to logging usually occurred in four groups of loggers: fellers, limbers, buckers, and material machine operators. Between October 1991 and May 1993, the NIOSH Fatality Assessment and Control Evaluation (FACE) program investigated 13 
fatal incidents that involved workers in the logging industry. The investigations revealed that many workers and employers in the logging industry were unaware of the risks associated with logging and were not following the procedures in the OSHA standards for preventing injuries and fatalities among loggers. This case report below summarized one of the exemplary incidents that were recently reported by FACE

"On January 6, 2004, a 68-year-old male tree feller (victim) died of injuries sustained when he was struck from behind by a tree which became entangled with the tree he was felling. He was in the process of felling a 65 foot red oak with substantial back lean. As he began cutting the tree, the victim did not use a hinge to control the fell and wedge to compensate for back lean. He was unable to use his wedge because it became buried under the butt of the tree he had felled earlier. As he finished his final cut, the tree set back and began falling opposite of the intended direction. Accordingly, he changed his escape path and retreated in the opposite direction. He stood approximately 12 feet from the stump to watch the fell, but as the tree fell, its top became entangled with a small diameter 70 foot tall black birch whose root system was weak. The oak pulled the birch over, striking the victim from behind. Witnessing the incident, his son responded by running down to the victim, cutting the birch off of him, and lying him down. Realizing the extent of his father's injuries, the son went to the landing and told a log truck driver to call 911. The driver stayed with the victim while the son waited to direct the ambulance. Approximately 30 minutes passed from the time of the incident until EMS arrived. The victim died shortly after their arrival and was transported to the nearest medical facility where he was pronounced dead."(FACE, 2004)

In another report for logging fatalities by the Occupational Safety and Health Administration (OSHA), a logging inspection report reveals that:

"On June 8, 2011, an employee, a 21-year-old male, was working alongside skidder operator with Back Country Logging who was moving a load of logs at the landing area, when the tire of the skidder made contact with a log on the ground. The log on the ground struck the employee on the back of the head and shoulder. The employee was killed in the event" (OSHA 2011)

In a study on Logger Safety conducted in 1995 at the West Virginia College of Law by Kelly Lee Holcomb, it was reported that "safety problems in the state were being underestimated by statistics for a number of reasons. Loggers without employees were not required to pay for Workers' Compensation and other companies and operations simply did not comply”. Holcomb also recalled that "the 1990 Census reported twice as many loggers in the state as workers' compensation figures report and some claims were not filed due to the fear of not losing jobs in companies where operators did not pay for workers' compensation." The Holcomb study also pointed out OSHA 
rules and state rules as other factors that influenced the safety of loggers in the past. The OSHA 1910.266 rules, which went into effect in February 1995, did not require training for all loggers, training was to be provided by the employer whenever loggers were assigned new work tasks, tools, equipment, machines or vehicles and whenever an employee demonstrates unsafe job performance. Also, the state required only a single certified logger to be in an establishment to issue a timber license and register the establishment. At that time, only the supervisor of each logging crew was trained for four hours by the West Virginia Division of Forestry (WV DOF).

By way of training comparison, mining in West Virginia is also recognized as a high hazard. Holcomb added in her report that "According to Webber (1995), director of the state Office of Miners' Health, Safety and Training (MHST), the coal industry at that time required every miner to be trained since 1968. Underground miners were to complete 80 hours of classroom training before entering a mine and also take eight hours of retraining each year to maintain their certification. He also said that "Prospective miners also require a score of more than 80 percent on a test to obtain an apprentice miner card. An apprentice miner must work as 'red hat' for six months, or 108 shift periods during which he must always be within the sight and sound of an experienced miner."

Given the discrepancy in training requirements of both occupations, Holcomb (1995) concluded that "it should not be far from expectation that the logging injury rates were higher than the rate of underground mining." Based on these findings, Holcomb proposed six changes to enhance logging safety in West Virginia, three of which suggested that:

i. "All loggers receive independent and continuous training in all of the areas in which injuries occurred and get a card.

ii. State officials keep track of what causes most logging injuries

iii. Logging companies that comply with safety training rules for all employees should be given lower workers' compensation rates.” Holcomb (1995) 


\subsection{Past Safety Efforts and Interventions}

\subsubsection{Criteria for Recommended Standard (NIOSH)}

NIOSH published Criteria for Recommended Standard in 1976: Logging from Felling to First Haul (NIOSH, 1976) recommended safe work procedures, personal protective equipment, and medical examinations to prevent logging related deaths and injuries. The recommendations stated that:

i. "Safety procedures in the OSHA regulations that apply to logging operations (29 CFR 1910.266) be followed

ii. A written safety program that includes: loggers training on proper felling techniques, safe work procedures for all tasks performed and instruction for workers to plan and clear retreat paths as necessary before beginning any cuts should be developed, implemented, and enforced.

iii. An initial and daily jobsite survey before beginning work be conducted to identify hazards and implement appropriate controls.

iv. A competent person must be designated to conduct periodic safety inspections to ensure that workers are performing their assigned tasks according to established safe work procedures and immediately correct any identified hazards or improper work practices.

v. Oversee the selection and use of logging tools/ equipment as well as the operation of machineries on site." (NIOSH, 1976)

\subsubsection{OSHA Logging Standards}

The OSHA standard for logging operations is found in 29 CFR 1910.266. OSHA's latest revision of the logging standards is in 2006 and it includes the following provisions for all loggers:

1. "Job training and certification for loggers 
2. Best practices and safe performance of all assigned work tasks (tree harvesting, manual felling, and loading and unloading, machine operations).

3. Extensive felling procedures ( proper techniques for undercuts and back cuts to prevent trees from prematurely twisting off the stump)

4. First-aid training for workers.

5. Use of personal protective equipment.

6. Strict requirements for the use of logging equipment" ( OSHA, 2006)

\subsubsection{Certified Logger Program}

The West Virginia's Certified Logger Program is a training and certification program which was initiated in 1992 and has since been coordinated by the WV DOF. The program includes classes on tree felling safety, personal safety equipment and best management practices (BMP). The requirement for all logging operations to have at least one certified logger on site for at least part of the day is believed to affect all logging establishments in a positive manner. This requirement also necessitate that establishments produce at least one certified logger through logging experience, training and certification provided through the WV DOF (WV DOF, 2001).

\subsubsection{Loggers' Safety Initiative}

The West Virginia Loggers Safety Initiative (LSI) was developed in July of 1999 to promote safe practices on professional logging operations with a designed performance monitoring system and a developed field inspection procedure for LSI participants (Carruth, 2000). OSHA states on its website that "The program was developed in an attempt to influence the cost of fatalities and injuries in the state at that time through the collaborative efforts of the West Virginia Forestry Association (WV FA), West Virginia Division of Forestry (WV DOF), West Virginia Occupational Safety and Health Administration (WV OSHA) office and the state's Workers Compensation Board 
(WV WCB). According to Francis (2002), the program was implemented for four years (19992002) with the goal of reducing the frequency and severity of logging-related accidents.

Some of the major features of the LSI program include:

- Loggers training and certification provided by WV DOF

- Outreach and training provided by OSHA in the applicable OSHA standards.

- Safety inspections by private consultants hired by the West Virginia Forestry Association.

- Grant money and incentives from the Workers Compensation Division to participating companies to improve safe work procedures.

Logging safety training topics covered were: safe chain saw operation, safe skidder operation, safe loader operation, log truck safety, first-aid and CPR training. OSHA agreed to provide training to loggers attending the training and to increase scheduled inspections at logging sites. The inspections determined whether the companies were complying with logging standards and implementing best practices. Logging companies belonging to the Forestry Association who sent their employees to training events and maintained high scores(about 80\%) at the end of training events and upon inspections per year received grants and 15\% discounts for workers compensation insurance rates from the West Virginia Workers Compensation Division. If a company receives a poor score on the inspection, it is removed from the LSI program (Francis, 2002).

\subsubsection{OSHA Enforcement}

Enforcing standards has been one of the most effective ways by which OSHA emphasized safe and healthy work conditions in various work places as developed under the Occupational Safety and Health Act of 1970. OSHA establishes safety and health regulations, encourages states to educate, train and inform employers to plan, prevent and protect their employees within the working environments. 


\subsubsection{Emphasis Programs}

OSHA describes its Emphasis Programs as enforcement strategies designed to focus on hazards or industries that pose a particular risk to workers within a region or area and the nation at large. Emphasis Programs basically involves intensified inspections to emphasize safety and outreach in the form of information sessions through trainings and events to increase awareness of safety issues. Emphasis programs implemented at the national level are referred to as National Emphasis Programs (NEPs) while those implemented at the region or area level are called Local Emphasis Programs (LEPs). NEP target areas include but are not limited to injury and illness recordkeeping, amputations, combustible dust, trenching and excavation. LEPs on the other hand targets high hazardous industries as: construction, logging and sawmill, oil and gas service, healthcare, metal recycling and waste handling, grain handling to mention a few.

\subsection{Local Emphasis Program for Logging in West Virginia}

In West Virginia, the WV OSHA LEP is currently implemented to target the logging industry which is being plagued by high fatality and workers' compensation claims rate. The activities of the program are being coordinated by the OSHA area office in Charleston West Virginia under the authority of the Pittsburgh regional office of OSHA (Region III). The LEP shares similar features with LSI which was earlier implemented in the state. The program consists of two main phases which include:

1. LEP Outreach Activities: Information sessions are held during the training classes organized by the West Virginia Division of Forestry to certify loggers. During the sessions, the appointed Certified Safety and Health Officers (CSHOs) from the Charleston area office answer questions and provide guidelines to loggers on compliance, LEP and logging safety matters. They also attend to queries, requests and offer technical information to logging groups as WVFA and enrolled logging establishments in the state (OSHA, 2011). 
2. Inspection: Following the outreach phase, Inspection activities are conducted in six districts of the state as listed and mapped by the West Virginia Division of Forestry (See Appendix $G$ ) these six districts are usually selected using a random numbers in table (See Appendix $G$ ) to determine the order in which the districts will be planned for inspection activity. The CSHO then contacts the West Virginia Division of Forestry and/or the US Forestry Service to determine the location of all of the active logging sites in that district which are then listed on the inspection register. Sites can be inspected in any order that makes efficient use of CSHO resources depending on situation and conditions. Each site on the register having logging operations are usually targeted for inspection once in a year except there are complaints, referrals or accidents requiring inspections (OSHA, 2011).

Employee complaints, referral and fatalities are handled in accordance with CPL 2.103, the federal OSHA Field Inspection Reference Manual (FIRM) and CPL 2.115, “complaint policies” and procedures. Other features of the program included in the directive are: recording of all inspection activities using the Integrated Management Information System (IMIS) and evaluating the program based on a set of selected activity and outcome measures (OSHA, 2011).

\subsubsection{Evaluation of the Current LEP}

According to the OSHA instruction for procedures of approval local emphasis programs (Directive CPL 04-00-001), all completed evaluation of LEPs must at a minimum address the LEP's role in meeting the goals of OSHA's strategic plan, to include: the number of employees covered, reduction in the number of injuries and illnesses, the number of workers removed from hazards, reductions in employee exposures, abatement measures implemented, number of violations related to specific targeted hazards. In addition, the evaluation must provide answers to the questions outlined in Appendix A of the instruction which includes: 
1. "What is the goal of the LEP?

2. In your opinion, did the LEP meet its goal? Was it highly effective, effective, less than effective, or ineffective or explanation if determination is not possible?

3. What data and information supports conclusion(s)?

4. Should the LEP be continued?

5. Have any legal issues arisen that should be brought to the attention of RSOL if the LEP is to be proposed for renewal?

6. Are there any other comments or recommendations?" (OSHA, 1990)

The originating area office is required to consider the following areas of information in making its response.

"Enforcement statistics as: number of inspections; number of inspections in compliance; number of "no inspection" cases and percentage of serious violations cited. It should also address: the number of employees covered by inspection; dollar amount of penalties assessed; percent of citations contested; number of significant cases; average violations per inspection; repeat violations, hazards that do not reappear once abated, cited standards, decline in illnesses and fatalities for establishments covered by LEP, industries covered, area or region covered impact on suppliers of production equipment and response of suppliers of production equipment to reduce exposure off users to injuries.

However, the directive permits that some of the subjects listed above may not apply to every LEP if they are not clearly applicable or no responsive information can be ascertained. But this should be so noted in the evaluation report."'(OSHA Instruction CPL 04-00-001, 1990)

In accordance to the OSHA Instruction CPL 04-00-001, Appendix A, the Charleston West Virginia area office like other LEP coordinating OSHA office prepares its written program evaluation considering the following activity measures and outcome measures:

\section{Activity Measures}

1. Number of inspections conducted.

2. Number, type and classification of violations per inspection.

3. Numbers of loggers attending training sessions. 
4. Numbers of employees removed from risk.

\section{Outcome Measures}

1. Reduction in the numbers of fatalities.

2. Implementation of a safety and health program by at least $75 \%$ of the employers inspected (OSHA 1999 and 2012).

\subsection{The Iceberg of Safety Theory}

The Heinrich's Iceberg Theory (1931), states that "fatalities are just the tip of the iceberg below which other less visible events occur more frequently". The base of the iceberg similar to a pyramid's base usually comprise of normal (unsafe behaviors), which occur more often and represents the base of an organizational system's normal operations. This model and others like it have been applied to address safety concerns both in an industrial and public setting. Examples of such instances are found in cases involving: "workplace safety (for each major injury there are 29 minor injuries and 300 near-misses, insured and uninsured costs), road incidents, preventable (1 death, 19 hospitalizations, and 300 minor health-cares) etc. (Perezgonzalez , 2011)

Although the actual numeric values are not reliable across industrial and service sectors, the Iceberg model can be applied as an heuristic to demonstrate that each accident or major event happens less often than less serious incidents, the less serious accidents similarly occur often less than near-misses or first aid cases, etc. The Iceberg Theory is also used as a preventative heuristic i.e. attention is given to minor incidents (near-misses, unsafe behaviors) and corrective actions are taken at that level to target the prevention of major incidents (death, injuries, property damage or loss). 
Despite the strengths of the model as described above, some critics believe that it may be weak in its application to contemporary safety. Robotham, (2004), in his article, "Why the Iceberg Theory has Misdirected Safety" argues that "incidents forming the base of the pyramid cannot be used as the main predictors of major incidents; rather the best way to predict and prevent major incidents is by examining other major incidents of equal magnitude." Geoff MacDonald (quoted in Robotham, 2004) also supported this notion in his article: "Occupational Personal Damage Causation" where he explained that "majority of mishaps can never get to be minor occurrences and vice-versa". He further explains that "though minor incidents form part of a predictive base but focusing on them has misdirected safety effort and resources in the past. He illustrated that "the common cold is not an indicator of deaths caused by heart failure, stroke, cancer or AIDS". Regardless of the arguments of the critics against the traditional safety model, both critics agree that near-misses and minor accidents cannot be ignored since they certainly have roles they play in predicting more serious damages. These are elements of safety ignored now in the current assessment of the WV LEP.

\subsection{Summary and Criticism}

There is an identified need to clarify why the current method of evaluating the LEP program is inadequate to determine the safety of loggers in the state. Apparently, safety is usually believed by some organizations to be a condition that keeps fatality rate to the minimum.

First, as illustrated by the Iceberg Theory, the risk of one fatality occurring in any industrial setting can be significantly reduced by focusing on reducing non-fatal occurrences involving injuries, first aid cases, near misses and unsafe conditions or behaviours within its system, which, in other words, means that safety is a function of both major and minor incidents that occur in an industry. For this reason, it can be concluded that the current evaluation method used by West Virginia for logging is weak in its function of helping the program achieve its goal of enhancing the safety of loggers because it does not include measures of important predictive indicators such as 
lost time injuries, first aid cases, near misses, unsafe behaviours and conditions which may better capture the risk of loggers being exposed to fatalities as suggested by the Iceberg theory. This research will use a larger and more varied data capture to suggest a method by which the program can be evaluated taking into account that modern day safety is not only the absence of fatal incidents occurring but is pivoted on the grounds that the risk of such incidents occurring is reduced to the minimal level possible.

Another explanation as to why fatality rates are poor indicators of this kind of program can be linked to the less likelihood of fatalities occurring compared to injuries and other safety related minor incidents. The observed low numbers of fatalities as some authors say limits the strength of evidence available to make better prediction in statistical analysis. The data pool is simply too small to make reliable statistical conclusions.

Secondly, examination of past loggers' programs involving models relating inputs to their outputs such as the LSI study by NIOSH shows an output is not a function of all inputs that are usually associated with it. Perhaps, this is another explanation for the conclusion that reduced incident rates and workers' compensation claims observed after the implementation of the LSI were or could have been as a result of mechanization and not the LS1 program (Bell 2003 and 2005). In other words, the observed safety outcomes of the LSI were significantly associated with mechanization and improved processes and not with the training and inspection factor of the program as initially thought by its organizers. 


\section{CHAPTER 3: RESEARCH DESIGN AND METHODS}

Following the review of existing literature, a study was built to quantify the relationships between the basic inputs of the LEP (rates of training, inspections) and desired safety outcomes (fatalities, injuries, violations, workers' compensation claims). This method of research was adopted to determine the safety outcomes that were most associated with the LEP program. Based on the study's objective and scope, the work done was carried out in two main steps:

1. Data acquisition from OSHA, WV DOF and WV IC

2. Determination of the best model which associates LEP variables to the desired safety outcomes for loggers.

\subsection{Research Design}

Jimmerson (2009) found that " the presence of hazards determine the level of fatal injuries along with employees' exposure to the hazards and how serious the hazards are in causing potential injuries". He continued that "hazard identification and risk assessment are the fundamental process input variables that result in injuries which translates into restriction and lost time that contribute to increased operating cost" Jimmerson also identified injuries and fatalities to be major occurrences that increase operating costs. These major occurrences represent high level inputs for operating costs which can be broken down into individual input variables.

Mathematically, the safety condition can be written as:

Equation 1: $\mathrm{Y}=\mathrm{F}(\mathrm{X})$

Thus the outcome $\mathrm{Y}$ is a function of the inputs $\left(\mathrm{X}_{1}, \mathrm{X}_{2}, \mathrm{X} \ldots \mathrm{Xn}\right)$

' $\mathrm{Y}$ ' represents one or a combination of the desired safety outcomes as: reduced fatalities, reduced injuries, reduced unsafe acts etc. 
' $\mathrm{X}$ ' represents any of the input variables that are thought to influence the safety outcomes as: training, inspections, mechanization, health care, work processes, environmental factors, etc.

In a similar framework for forming models, a quantitative approach to the research enabled the study to use available loggers' safety data to create various statistical models to investigate the effect of the LEP inputs (independent variables: training and inspection of loggers) on desired safety outcomes (dependent variables: fatality rates and incident rates).

\subsection{Data collection}

Loggers' incident and compensation data were collected through OSHA and WC IB database for the West Virginia logging industry. Inspection, violation and fatality reports of loggers in West Virginia were obtained by using the North American Industry Classification System (NAICS) code for logging (113310) to search the OSHA directorate of enforcement programs database. Worker compensation and injury claims' records for the logging industry were requested from the West Virginia Insurance Commission. Workers' compensation claims data were used to represent unavailable injury data for the logging industry because injury data for loggers were not retrievable through OSHA and BLS websites due to the fact that most West Virginia logging firms with small number of employees were not required by OSHA to report injuries. (OSHA). During this research, contacts were made with the WV DOF to obtain Loggers' training, logging operation notification and timber license data. The numbers of timber license holders for each year were used to account for the number logging establishments that were present in the state.

\subsection{Statistical Methods}

To analyze the collected data for possible relationships between input and output variables, there was need to sort the raw data recorded for 10 years (2003-2012) by variable types (dependent 
and independent). Past studies (Doane and Seward, 2009) show us that there are two types of analysis that can be done to determine the type of relationship that exists between variables. The first analysis considers the strength and direction of relationship that exist between variables. This type of analysis known as "correlation" in statistics usually establishes any form of relationships between variables where it exists. Correlation is a statistical method that indicates how pairs of variables are related especially in linear relationships. The parameter, correlation coefficient " $r$ " is the result that measures correlation between variables. It ranges from -1.0 to +1.0 . Variables are strongly related if ' $r$ ' is closer to +1 or $-1,(0.95,-0.88$ for examples $)$. An observed ' $r$ ' close to 0 $(-0.15,0.08$ for examples) indicates a weak relationship between the variables and $\mathrm{r}=0$ indicates lack of correlation between the variables. A positive sign for ' $r$ ' means that both pair of variables increase or decrease together with time (direct relationship) while a negative ' $r$ ' means that one variable increases as the other decreases with time (inverse relationship).

The square of ' $r$ ' called the 'coefficient of determination' is another parameter which shows how much variation in one variable relates to the variation in another. It is however important to note that correlation does not imply causation meaning that a change in one variable does not cause change in another (Doane and Seward, 2009).

The second analysis shows the level of impact of one variable on another. This analysis is called "regression". A regression analysis is used to find a model equation that will predict a dependent variable using one or more independent variables. In this study, a bi-variate analysis which assumes a linear relationship between two variables: independent variable $\mathrm{X}$ (predictor) and the dependent variable Y (response) (Doane and Seward, 2009), was considered to find how each particular input variable predicted the output variables.

It can be represented mathematically as:

Equation 2: $\quad \mathrm{M}_{\mathrm{X}, \mathrm{Y}} \rightarrow \mathrm{Y}=\beta 1 \mathrm{X} 1+\beta 2 \mathrm{X} 2+\ldots+\alpha$ 
Where:

$\mathrm{M}_{\mathrm{X}, \mathrm{Y}}$ represents the model involving input $\mathrm{X}$ and output $\mathrm{Y}$

$\mathrm{Y}$ is the predicted response

$\mathrm{X} 1$ and $\mathrm{X} 2$ are the independent variables used to predict $\mathrm{Y}$

$\beta 1$ and $\beta 2$ are coefficients that describe the size of the effect the independent variables are having on the dependent variable.

' $\alpha$ ' is the intercept and is the value of the dependent variable when the value(s) of the independent variables are 0 .

In addition to the explanations above, it is important to note that there exists a relationship between both types of analyses, regression analysis as a method is capable of achieving its full purpose on the basis that both dependent and independent variables possess a level of correlation to show the strength of association between both variables. Coefficients ( $\beta 1$ and $\beta 2)$ of independent variables not equal to ' 0 ' show that independent variables have a significant effect on the dependent variables while those equal to 0 is said not to have significant impact on the dependent variables.

A parameter known as ' $\mathrm{P}$ ' is used to test the significance of regression results. For every regression analysis, the default hypothesis is the null hypothesis which shows that each independent variable is having no effect on dependent variables in other words; the independent variable has a coefficient of zero. Ideally, researchers using this method of analysis will always look for a reason to reject this hypothesis to ascertain the impact of the independent variable on the dependent variable (Doane and Seward, 2009). .

Equation 3: Null Hypothesis $H_{0}: \beta 1=\beta 2=0$

Equation 4: $\mathrm{H}_{1}: \beta 1, \beta 2 \neq 0$ 
Therefore, the test for significance of a model produced by regression is represented by ' $\mathrm{P}$ ' such that $\mathrm{P}$ value $\leq 0.05$. This point represents a generally accepted point to reject the null hypothesis which gives a $95 \%$ confidence interval that the estimated coefficient value is not 0

\subsection{Data Analysis}

Collected data was analysed with the aid of Microsoft Excel, Minitab and SAS computer programs. Models combining various independent and dependent variables were derived to show possible associations and interactions. For each model identified and analysed with regression, the intercept $(\alpha)$, Beta values $(\beta)$, Coefficient of determination ( $R^{2}$ values), $P$ values and line of best fit plots were obtained.

Supported by statistics obtained on analysis, the responses of model tested were compared and the best fit model was selected based on how significantly the basic program elements (Training and Inspection) influenced the desired outcomes. The final decision for selecting the best model took into consideration the following criteria:

1. The strength and consistency of correlation or association that existed between the independent variables and the response outcomes.

2. The amount of variance in the desired outcomes predicted by the independent variables, (high $\mathrm{R}^{2}$ values with and only with $\mathrm{P}$ values $\leq 0.05$.)

3. The strongest response with a measure of severity.

\subsection{Data Presentation}

Ten years data (2003 - 2010) were collected and examined. Raw numbers of training, inspection, violation, fatality and workers' compensation claim data were used to derive rates based on the number of establishments or timber licence holders and number of logging operations for an in-depth analysis. Inspection rates were calculated with number of inspections in the numerator in 
the numerator and number of logging operations in the denominator. Rates of training, violations, fatality and workers' compensation injury claims were calculated with the number of timber license holders in their denominator. The data was sorted out by years (rows) and arranged by variable type in columns using the excel spread sheet sorting and calculation functions (MS Excel 2010).

West Virginia Division of Forestry provided information and data on the number of timber license holders and number of logging notifications that were received on a yearly basis. (See Table 1). The agency also provided data of loggers' trained and certified for 10 years. (See Table 2). Inspection data presented in the study were obtained from OSHA's data and statistics which can be found on line at OSHA's website (See Table 3).

The number of violations found on each inspection and the number of fatalities that occurred each year were extracted from the inspection reports for various establishments.

Tables 1 and 2 show a decrease in the number of timber licenses and certified loggers over time, this occurred during some time because trainings at that time were valid for three years. So, every three years, loggers have to take training to keep their trainings up to date when they renew their certified logger. But now, training is valid for 4 years after which loggers are required to renew their certifications. The number of timber licenses for that time period which indicates the number of registered logging companies also declined over due to the high price of timber and less demand.

Ten years' worth of loss data was requested from WV IC, but only five (5) years (20062010) data for workers' compensation injury claims and costs were provided. More current information could not be provided due to the restricted reporting requirements for insurance carriers. This reduced the number of observations and entries that could be used to test models involving injury claims and costs to five years.

From the raw data provided, rates were calculated with denominators that would make stronger analyses. 
The number of logging operations was used as denominator for the number of total and planned inspections for each corresponding year. Likewise, rates were calculated for loggers trained, fatality, violations found during inspections, injury claims and medical costs using the number of timber license holders as the denominator.

Last, the rates of unplanned inspections (due to accidents and complaints) were calculated using the number of total inspections as the denominator. All the calculated rates were compiled to form a database which was fed into the computer programs for the statistical analysis.

To fulfil the objective of applying the Iceberg theory, four measures of safety were targeted for the analysis. Fatality rates were used as a measure of fatalities; workers' compensation claims and costs were used as a measure of injuries and severity. Repeat violations and number of unplanned inspections were used as a measure of unsafe acts/conditions of loggers.

Thus the following variables were used to generate possible test models in the research:

\section{Program Inputs}

X1= Training per Timber License Holders (rates)

$\mathrm{X} 2=$ Inspections per Logging Operations (rates)

X3=Rates of Planned Inspections per Logging Operations (rates)

\section{Desired Safety Outcomes}

Y1= Fatality per Timber License Holders (rates)

Y2= Injury/Claims per Timber License Holders (rates)

Y3= Medical costs per Timber License Holders (rates)

Y4= Rates of total violations (Serious +repeat+ others) per Timber License Holders

Y5= Repeat violations per Total Inspections (rates)

Y6= Cost of total violations per Timber License Holders (rates)

Y6= Unplanned inspections per Total Inspections (rates) 
Test models were assigned numbers according to the type of input and outcome being associated. For examples:

$$
\begin{aligned}
& \mathrm{M}_{1,1} \rightarrow \text { Having input } \mathrm{X} 1 \text { and Outcome } \mathrm{Y} 1 \\
& \mathrm{M}_{3,4} \rightarrow \text { Having Input X3 and Outcome Y4 } \\
& \mathrm{M}_{1,2,3} \rightarrow \text { Having Inputs X1 and X2 and Outcome Y3 }
\end{aligned}
$$

Following the identification of test models with unique input and output relationship, the models were tested for correlation using Minitab 16 software. This generated reports which displayed resulting Pearson correlation coefficient ' $\mathrm{r}$ ' for each model tested $\mathrm{In}$ addition to the Pearson correlation coefficient ' $r$ ' results, the generated correlation reports in each case also showed a second result for significance level (P value- statistical significance). Thus, Pearson correlation ' $r$ ' values and significance test ' $\mathrm{P}$ ' values were determined for each model. The P-Value was utilized to test the significance level of each model. Models with significant levels i.e. $\mathrm{P} \leq 0.05$ were further analyzed for regression using SAS software. Overall, Thirty-seven models were used in this study, thirty five (35) of which were tested with correlation and regression to find the output with the highest explanatory power while two additional models were used to relate the identified output variable with highest explanatory power to the most influential input variable to form the final model that will be suggested for future use. 
Table 1:

Timber license holders and Notifications for Logging Operations that were received by WV DOF in West Virginia over the years

\begin{tabular}{|r|r|r|}
\hline & Timber Licenses & $\begin{array}{l}\text { Notifications for Logging } \\
\text { Operations }\end{array}$ \\
\hline 2003 & 1,310 & 3,417 \\
\hline 2004 & 1,447 & 3,570 \\
\hline 2005 & 1,459 & 3,528 \\
\hline 2006 & 1,361 & 3,271 \\
\hline 2007 & 1,232 & 2,855 \\
\hline 2008 & 1,194 & 2,532 \\
\hline 2009 & 1,006 & 2,118 \\
\hline 2010 & 964 & 2,149 \\
\hline 2011 & 898 & 2,005 \\
\hline 2012 & 901 & 1,853 \\
\hline & &
\end{tabular}

(WV DOF, 2012)

Table 2:

Loggers Trained and Certified in the WV DOF Certified Loggers Training Program over Years

\begin{tabular}{|c|c|c|}
\hline Year & Trained Loggers & Certified Loggers \\
\hline 2003 & 1,290 & 1,579 \\
\hline 2004 & 1,290 & 1,705 \\
\hline 2005 & 1,513 & 1,754 \\
\hline 2006 & 1,303 & 1,704 \\
\hline 2007 & 1,295 & 1,627 \\
\hline 2008 & 1,289 & 1,602 \\
\hline 2009 & 829 & 1,397 \\
\hline 2010 & 1,006 & 1,310 \\
\hline 2011 & 1,065 & 1,188 \\
\hline 2012 & 619 & 1,184 \\
\hline
\end{tabular}

(WV DOF, 2012) 
Table 3:

OSHA inspections at logging sites, violations and fatalities recorded over the years

\begin{tabular}{|r|r|r|r|r|r|r|r|r|}
\hline & \multicolumn{9}{|c|}{ Inspections } & \multicolumn{5}{c|}{ Violations } & Fatality \\
\hline Year & \multicolumn{1}{|c|}{ Total } & Planned & Accident & Complaint & Total Violations & Cost of Violation(\$) & Repeated Violations & Counts \\
\hline 2003 & 52 & 44 & 4 & 1 & 295 & 92590 & 13 & 4 \\
\hline 2004 & 79 & 63 & 5 & 5 & 467 & 161215 & 32 & 5 \\
\hline 2005 & 94 & 75 & 2 & 5 & 465 & 127750 & 27 & 2 \\
\hline 2006 & 120 & 109 & 1 & 1 & 529 & 213590 & 28 & 1 \\
\hline 2007 & 75 & 59 & 6 & 2 & 343 & 115805 & 13 & 5 \\
\hline 2008 & 59 & 52 & 0 & 6 & 218 & 117020 & 2 & 0 \\
\hline 2009 & 24 & 23 & 1 & 0 & 87 & 47165 & 6 & 1 \\
\hline 2010 & 39 & 31 & 3 & 2 & 71 & 55415 & 0 & 3 \\
\hline 2011 & 21 & 16 & 2 & 1 & 62 & 86627.5 & 6 & 1 \\
\hline 2012 & 11 & 6 & 2 & 1 & 17 & 8640 & 0 & 0 \\
\hline
\end{tabular}

(OSHA, 2012)

Table 4:

Loss data for NCCI classes $2702 \& 2709$

Loss Data

Classes 2702 and 2709 for Logging or Tree Removal

\begin{tabular}{|l|r|r|r|r|}
\hline Policy Period & \multicolumn{1}{|l|}{ Injury Claims } & \multicolumn{1}{l|}{ Cost of Injury Claims(\$) } & \multicolumn{1}{l|}{ Medical Cost(\$) } & \multicolumn{1}{l|}{ Payroll } \\
\hline $2005-2006$ & 0 & 0 & 0 & 0 \\
\hline $2006-2007$ & 88 & $3,346,302$ & $2,386,729$ & $17,682,234$ \\
\hline $2007-2008$ & 69 & $1,038,462$ & $2,091,106$ & $16,009,761$ \\
\hline $2008-2009$ & 43 & $1,070,408$ & $1,899,104$ & $11,797,352$ \\
\hline $2009-2010$ & 37 & 744,203 & $1,943,247$ & $10,551,673$ \\
\hline
\end{tabular}

Class code: 2702 - Logging or Tree Removal: Non Mechanized Operations

Class code: 2709 - Logging or Tree Removal: Mechanized Equipment Operator 


\section{CHAPTER 4: RESULTS AND DISCUSSION}

\subsection{Tests and Results}

Following the statistical analysis, the coefficient of correlation ' $r$ ', coefficient of determination ' $\mathrm{R}^{2 \text {, }}$ and $\mathrm{P}$ value for each model tested was noted and recorded in a table. See Table 5

Table 5: Results of Statistical Analysis

\begin{tabular}{|c|c|c|c|c|c|}
\hline & Variables & $\begin{array}{l}\text { F(X1)=Trained } \\
\text { Loggers/Timber } \\
\text { Licence Holders }\end{array}$ & $\begin{array}{l}F(X 2)=\text { Total } \\
\text { Inspections/Logging } \\
\text { Operations }\end{array}$ & $\begin{array}{l}F(X 3)=\text { Planned } \\
\text { Inspections/Logging } \\
\text { operations }\end{array}$ & $\mathrm{F}(\mathrm{X} 1$ and $\mathrm{X} 2$ or $\mathrm{X} 3)$ \\
\hline Y1 & $\begin{array}{l}\text { Fatality / Timber } \\
\text { Licence Holders }\end{array}$ & $\begin{array}{l}P=0.528 \\
r=0.227\end{array}$ & $\begin{array}{l}P=0.537 \\
r=0.222\end{array}$ & $\begin{array}{l}P=0.788 \\
r=0.098\end{array}$ & $\begin{array}{l}P 2=0.798 \\
P 3=0.828\end{array}$ \\
\hline $\mathbf{Y 2}$ & $\begin{array}{l}\text { Injury claims/ } \\
\text { Timber Licence } \\
\text { Holders }\end{array}$ & $\begin{array}{l}P=0.526 \\
r=0.381\end{array}$ & $\begin{array}{l}P=0.439 \\
r=-0.457\end{array}$ & $\begin{array}{l}P=0.323 \\
r=-0.563\end{array}$ & $\begin{array}{l}P 2=0.440 \\
P 3=0.396\end{array}$ \\
\hline Y3 & $\begin{array}{l}\text { Medical costs / } \\
\text { Timber Licence } \\
\text { Holders }\end{array}$ & $\begin{array}{l}P=0.173 \\
r=0.781\end{array}$ & $\begin{array}{l}P=0.099 \\
r=-0.807\end{array}$ & $\begin{array}{l}P=0.044 \\
r=-0.888 \\
R^{2}(\operatorname{adj})=71.9 \% \\
Y 3=3289-88695 \times 3\end{array}$ & $\begin{array}{l}P 3=0.048 \\
R^{2}(\text { adj })=90.3 \% \\
Y 3=107-98873 \times 3+3415 \times 1 \\
P 2=0.092 \\
R^{2}(\operatorname{adj})=81.6 \% \\
Y 3=-822-91150 X 2+4490 \times 1\end{array}$ \\
\hline Y4 & $\begin{array}{l}\text { Violations/ Timber } \\
\text { Licence Holders }\end{array}$ & $\begin{array}{l}P=0.603 \\
r=0.188\end{array}$ & $\begin{array}{l}P=0.001 \\
r=0.886 \\
R^{2}(\operatorname{adj})=75.8 \% \\
Y 4=-0.0472+12.4 X 2\end{array}$ & $\begin{array}{l}P=0.001 \\
r=0.863 \\
R^{2}(\operatorname{adj})=71.3 \% \\
Y 4=-0.0194+13.3 \times 3\end{array}$ & $\begin{array}{l}P 3=0.008 \\
R^{2}(\text { adj })=68.1 \% \\
Y 4=0.051+13.7 \times 1-0.079 \times 3 \\
P 4=0.004 \\
R^{2}(\text { adj })=74.0 \% \\
Y 4=0.048+13.0 \times 1-0.109 \times 3\end{array}$ \\
\hline Y5 & $\begin{array}{l}\text { Repeat } \\
\text { violations/Timber } \\
\text { Licence Holders }\end{array}$ & $\begin{array}{l}P=0.878 \\
r=0.056\end{array}$ & $\begin{array}{l}P=0.036 \\
r=0.835 \\
R^{2}(\operatorname{adj})=37 \% \\
Y 5=-0.00216+0.600 X 2\end{array}$ & $\begin{array}{l}P=0.046 \\
r=0.640 \\
R^{2}(\operatorname{adj})=33.6 \% \\
Y 6=-0.00073+0.635 \times 3\end{array}$ & $\begin{array}{l}P 2=0.829 \\
P 3=0.828\end{array}$ \\
\hline Y6 & $\begin{array}{l}\text { Cost of violations/ } \\
\text { Timber Licence } \\
\text { Holders }\end{array}$ & $\begin{array}{l}P=0.124 \\
r=0.519\end{array}$ & $\begin{array}{l}P=0.003 \\
r=0.835 \\
R^{2}(\operatorname{adj})=66 \% \\
Y 6=12.1+3612 \times 3\end{array}$ & $\begin{array}{l}P=0.002 \\
r=0.849 \\
R^{2}(\operatorname{adj})=68.5 \% \\
Y 6=17.45+4020 \times 3\end{array}$ & $\begin{array}{l}P 2=0.006 \\
R^{2}(a d j)=69.6 \% \\
Y 6=54.3+13.7 \times 2-0.079 \times 1 \\
P 3=0.004 \\
R^{2}(a d j)=73.4 \% \\
Y 6=-55.3+3604 \times 3-79.6 \times 1\end{array}$ \\
\hline Y7 & $\begin{array}{l}\text { Unplanned } \\
\text { Inspections (due to } \\
\text { accidents and } \\
\text { complaints/Total } \\
\text { Inspection) }\end{array}$ & $\begin{array}{l}P=0.152 \\
r=\underline{-0.356}\end{array}$ & $\begin{array}{l}P=0.039 \\
r=\underline{-0.658} \\
R^{2}(\operatorname{adj})=36.2 \% \\
Y 7=0.208-4.94 X 2\end{array}$ & $\begin{array}{l}P=0.017 \\
r=\underline{-0.726} \\
R^{2}(\mathrm{adj})=46.8 \% \\
Y 7=0.208-5.97 \times 3\end{array}$ & $\begin{array}{l}P 3=0.025 \\
R^{2}(\text { adj })=95.1 \% \\
Y 7=-0.256-3.73 \times 3+0.413 \times 1 \\
P 2=0.054 \\
R^{2}(\text { adj })=89.3 \% \\
Y 7=-0.290-3.40 \times 2+0.452 \times 1\end{array}$ \\
\hline
\end{tabular}

*Best fit models-Deep Green ${ }^{*}$ Good fit models with $\mathrm{P}<0.05$-Light Green

*Fair or border line models with $\mathrm{P}=0.05$-Yellow *Models with negative correlation- Underlined 


\subsection{Discussion of Results}

Of the first 35 models that were tested, there were 15 models with high significance levels $(\mathrm{P}<0.05)$ and 19 with low significant levels and one $\left(\mathrm{M}_{1.2,7}\right)$ was on the border line with a fair significance level (about 0.05). Models with negative correlations were 7: (Models: $\mathbf{M}_{2,2}, \mathrm{M}_{3,2} \mathrm{M}_{2,3}$ $\mathrm{M}_{3,3} \quad \mathrm{M}_{1,7} \mathrm{M}_{2,7} \mathrm{M}_{3,7}$ ) while the remaining 28 produced positive correlations. Significant models showing negative correlations were 3; $\left(\mathrm{M}_{3,3} \mathrm{M}_{2,7} \mathrm{M}_{3,7}\right)$. Total significant models showing negative correlations with very high $\mathrm{R}^{2}$ values were two $\left(\mathrm{M}_{3,3} \mathrm{M}_{1,3,3}\right)$

According to general statistical rules, models with high significance levels $(\mathrm{P} \leq 0.05)$ were considered to be a predictor on the first level of the test. Thus, from the table of results, it can be seen that all the outcomes in this study with the exception of fatality, injury claims and repeat violations were of good fits with the inputs: total inspections and planned inspections.

Significant models showing positive correlations revealed the real situation with the LEP's inspection activities; the more inspections that were conducted, the more violations were cited and more fines paid by loggers.

Significant models showing negative correlations reveal the ideal situation for an implemented effective LEP program. The more inspections were planned, the lesser medical costs that were paid by loggers due to injuries sustained. The more inspections were conducted, the lesser inspections due to accidents and complaints occurred. These negative correlations are the expectation.

Models involving fatality and injury claims were neither significant nor showed any association with training and inspections conducted previously.

Although there were not many differences in most results of significant models that involved planned and total inspections, the analysis revealed in models $\left(\mathbf{M}_{1,3} \mathbf{M}_{1.3,3}\right.$ and $\left.\mathbf{M}_{1.3,7}\right)$ that planned inspections were of higher significance than total inspections showing a more ideal response to medical costs and unplanned inspections due to accidents and complaints, both of which 
represent measures of severity and unsafe acts and conditions. In both cases, there was also an observed improvement in their explanatory powers ' $\mathrm{R}^{2}$, when training was involved. Using the given criteria in the method section of this report, it can be concluded that models involving medical costs are the best due to its high explanatory power, very strong negative correlations to LEP inputs and consistency of results which makes a true representation of an ideal situation

Finally, in an additional model which was tested, a correlation of workers' compensation claims and medical costs showed high significance and strong positive correlation meaning that workers' compensation claims can be expected to be high given high medical cost and vice versa.

\section{Correlations: claims, medical costs}

Pearson correlation of claims and medical costs " $r$ " $=0.953$

P-Value $\quad=0.047$

\section{Regression Analysis: claims versus medical costs}

The regression equation is:

Claims $=-154+0.000102$ medical costs

Thus, from the findings of the research explained above, the suggested final improved model for tracking the success of the program will be:

Severity $($ Workers compensation claims $)=>\alpha_{o}+\beta_{o} \sum[$ (medical costs /logging establishments $=\alpha_{a}-\beta 1_{a}$ Planned Inspections/logging operations $+\beta 2_{a}$ Trained Loggers/ Timber License Holders $)+\left(\right.$ Unplanned Inspections $=\alpha_{b}-\beta 1_{b}$ Planned Inspections/ logging operations $+\beta 2_{b}$ Trained Loggers/ Timber License Holders)]

(Note: The intercept and coefficient parameter values $(\alpha, \beta)$ are subject to change over time Also the improved model is based on the assumption of linear relationships between program inputs and desired safety outcomes.) 
The model above suggests that a measure of severity be the outcome of the program (for example, workers' compensation claims) where the major output can be rates of unplanned inspections per total number of inspections in addition to medical costs per timber license holders while rates of planned inspections per logging operations and loggers trained per establishments be the major program inputs to track success of the LEP as it relates to loggers' safety.

\subsection{Study Limitations:}

Various limitations were encountered in the course of this study most of which were related to poor database for loggers' employment and safety data. Injuries with lost days' record for loggers for years that were examined were not accessible and loss data for loggers in the state were not available for all 10 years needed to represent inspection reports in the state. It was also difficult to determine the exact time the LEP was first implemented in the state to do a pre and post-analysis of its effectiveness as most officials in the state were not aware of the commencement of the program. Specific training records and employment information of registered loggers in the state could not be accessed as well.

Timber licenses were used to represent active logging establishments on the premise that all registered logging establishments were timber license holders. But there are three types of timber licences; Timber Operator for logging operation on site, Timber Buyer for trading logs and timbers and the last is a Combined License for people who are involved in both timber operations and $\log$ trades. So, using numbers for the total license holders may not precisely correspond to total number of establishments performing actual logging operations at site.

Also, due to the lack of non-fatal injury records with days transferred or lost from work, loss data; workers' compensation claims and medical costs were the only data source through which injuries for the industry were monitored. 
Last, it is important to note that, despite the study's attempt to find safety outcomes that were most influenced by training and inspections; there still exist confounding factors such as work processes, health care, mechanization, weather conditions, demographics etc. with influences on the desired safety outcome which cannot be determined within the scope of this study. 


\section{CHAPTER 5: CONCLUSIONS AND RECOMMENDATIONS}

\subsection{Conclusion}

In summary, loggers' safety data was analysed to propose an improved richer predictive model by which the WV OSHA LEP may be evaluated. Tracking the risk of loggers being exposed to serious health hazards was emphasized rather than focusing on the reduction of fatalities particularly given the limited uses of fatality data alone. First, following the Iceberg theory of Safety, it was suggested that the current measures used in evaluating the program were inadequate in capturing the actual safety conditions of loggers and their businesses, i.e. only fatalities stood out "above the water line" when more useful data, if accessible were below it. Based on the theory, injury rates, workers' compensation claims, violations and Days Away, Transferred or Restricted Work (DART) were proposed as additional safety outcomes to incorporate additional risk factors which will be tracked in an improved evaluation model.

Secondly, it was necessary to build a model by which desired safety outcomes observed can be most attributed to the success of the LEP. In fact, another advantage of the proposed model would be to identify a safety condition that is most influenced by the LEP factor amongst other possible influencing factors as improved work procedures, medical care, mechanization, etc., for which similar safety outcomes may result or be observed.

To achieve the research objectives, a quantitative research approach was used to collect loggers' safety data for ten years (2003-2012). Data were obtained from OSHA, WV DOF and WV IC for ten years that the program was believed to have matured. The collected data were sorted into groups of independent and dependent variables, using Microsoft Excel 2010 spread sheet functions. Bivariate regression methods were used to analyse data pattern with the aid of SAS and Minitab computer programs. With the support of resulting analysis, models which showed strong associations between the LEP inputs (training and inspections) and identified safety out comes were 
presented and discussed. The model of best fit between program variables and desired outcomes was selected from other identified good models by comparing their overall resulting statistics.

The findings of the study are summarized as follows:

1. Of all 35 models that were initially tested, there were 15 models with suitable significance levels $(\mathrm{P}<0.05)$, one model with borderline significance and 19 with low significant levels. Outcomes involved in significant models were: medical costs, total violations, repeated violations and unplanned inspections (due accidents and complaints). The most significant program input was inspection as training did not correspond with high significance for most desired outcomes. Models that involved planned inspections showed higher significance when compared to models involving total inspections indicating its higher explanatory power for the desired outcome.

2. The outcome with the highest explanatory power and most consistent response to the LEP input variables for an ideal situation was medical costs.

3. Fatality and injury claims did not show good responses to LEP inputs (training and Inspection).

Based on these findings, this study concludes that there is evidence that the use of fatality rates and loggers participation in the LEP training program as used by WV OSHA is not especially useful to track the success of the program. Though the current evaluation method helps WV OSHA to meet the guidelines of the Federal OSHA strategic goal for LEP, it does little to measure the impact of the program on the safety of workers in the logging industry. A better model to evaluate the LEP will include medical costs of all injuries, planned inspections and unplanned inspections including employee complaint and accident inspections

\section{$5.2 \quad$ Recommendations}

While some part of the analysis has shown that the LEP may be effective in reducing medical costs of injuries and unplanned inspections (due to accidents and complaints) which 
corresponds to severity and unsafe acts/conditions of loggers for this research, it is necessary that OSHA clarify the expectations of the program by establishing concrete and measurable goals that relate to the current safety conditions of loggers to ensure its proper evaluation. These do not rely only upon fatalities given the vagaries associated with their method of progress assessment. OSHA should focus on reducing the risk of loggers being exposed to fatal injuries by tracking and monitoring the progress of leading and lagging indicators that best fits the program. Just as the research suggests, a measure of severity should be made the outcome of the program (loss data such as claims rate, DART rates). While rates of unplanned inspections (due to accidents, complaints and follow ups) in addition to medical costs be used as major output with rates of planned inspections per logging operations and loggers trained per establishments being the major program inputs to track the success of LEP. In order to achieve this, three things OSHA should consider include:

\section{Provision of adequate inspection activities to cover all registered logging establishments:}

The availability of inspectors for the implementation of the enforcement program is perhaps an indicator that should be associated with the activity measures of the program (OECD, 2008). In 2012, only six planned inspections were carried out in the state of West Virginia out of about 900 logging operations that were reported to WV DOF. From this study, significant responses that did not show negative correlations, revealing the effectiveness of program elements were related to lack of resources needed by the OSHA area offices to plan adequate inspections to cover all logging operations by logging establishments. According to OSHA Charleston office, lack of inspectors and under-canopy loggers who do not register their operations as appropriate nor participate in the LEP training were the sources of the low inspection problem being experienced in the state. The success of an enforcement program is pivoted on the peoples' awareness that they are being 
constantly monitored or policed by assigned government officials. The unavailability of inspectors in the state is also likely to impact actions or behavior of trained loggers at logging operation sites that do not have such coverage. In the absence of inspectors for certain logging sites, OSHA may collaborate with researchers to check if instrumentation such as cameras can be used to capture data and monitor a logging operation event. OSHA should also work with the West Virginia Office of Commerce to consider ways by which unlawful logging operations in the state can be discouraged such as organizing a special incentive program where incentives will be given to timber and wood product buyers for patronizing establishments that are well known for their consistent participation in the LEP training and inspection activities.

\section{Enhancement of loggers' safety records and database:}

The WV OSHA area office should work with the WV DOF, WVIC, BLS and other state government agencies to address the lacking state of loggers' safety records and database in the state. The extent to which safety data are kept, available and retrievable determines the basis for improving safety. Safety records should include relevant safety information and be available for all activity and outcome metrics. OSHA should always request data related to injuries, near misses, first aid cases and other minor occurrences from registered establishments. This will allow for easy retrieval of safety information necessary for OSHA officials and future researchers to evaluate the success of the program with greater accuracy.

\section{Constant review of activity and outcome measures:}

Finally, OSHA should review regularly the full scale of metrics associated with the program's activity and outcome measures to continuously improve on their model of evaluation, not just fatalities, inspections and training. 


\section{REFERENCES}

Bell, JL.(2002). Changes in logging injury rates associated with use of feller-bunchers in West Virginia. Journal of Safety Research2002; 33:463-471.

Bell, JL, Helmkamp JC. (2003). Non-fatal injuries in the West Virginia logging industry: Using workers' compensation claims to assess risk from 1995 through 2001. American Journal of Industrial Medicine 44(5):502-509.

Bell, JL. (2005). Mechanical timber harvesting reduces workers' compensation injury claims in West Virginia. April 2005. DHHS (NIOSH) Publication No. 2005-19.

Bureau of Labor Statistics 'BLS' (2012): National census of fatal occupational injuries in 2011 Preliminary results, pp.5.< http://www.bls.gov/news.release/pdf/cfoi.pdf > accessed 27 November, 2012).

Bureau of Labor Statistics 'BLS' (2013): National census of fatal occupational injuries in 2011. Hours-based fatal injury rates by industry, occupation, and selected demographic characteristics, pp.2.< http://www.bls.gov/iif/oshwc/cfoi/cfoi_rates_2011hb.pdf > accessed 22 June, 2013).

Carruth, S. (2000). 'West Virginia Loggers Safety Initiative; loggers, mills, and government cooperate on loss control'. Forest Operations Review; 2 (2):8-14 (spring/summer).

Carolee , B. (2001). 'West Virginia Safety Initiative Is Recognized'. Timberline <http://www.timberlinemag.com/articledatabase/view.asp?articleID=598> accessed 28 November 2012

Doane, DP. and Seward LE.(2009). Applied Statistics in Business and Economics, $2^{\text {nd }}$ ed. McGraw-Hill Education, USA

Francis, CB. (2002). West Virginia's Logging Safety Initiative. National Timber Harvesting and Transportation Safety Foundation, (Accessed 27 November, 2012)

http://loggingsafety.com/content/west-virginias-logging-safety-initiative

Helmkamp, JC, (1999). Nonfatal logging-related injuries in West Virginia. Journal of Occupation and Environmental Medicine 1999; 41:967-72

Holcomb, KL.(1995). Loggers' Safety. Available at the West Virginia College of Law, August 1995

Heinrich, H W. (1931). Industrial accident prevention, a scientific approach, $4^{\text {th }}$ ed. McGraw-Hill Book Company, New York, USA.

Jimmerson, G.(2009) Safety Process Improvements: Professional Safety Journal. Journal of the American Society of Safety Engineers. Volume 54, Number 6. June 2009

Myers, JR. and Fosbroke, DE.(1994). Logging fatalities in the United States by region, cause of death and other factors B 1980 through 1988. Journal of Safety Research1994;25: 97-105. 
NIOSH (1995). Preventing Injuries and Death, Centre for Disease Control and Prevention, DHHS (NIOSH) Publication, 95-101< http://www.cdc.gov/niosh/docs/95-101/>

OSHA (2006). Logging standard 29CFR1910.266. US Department of Labor, Washington, DC. April 3, 2006.

<http://www.osha.gov/pls/oshaweb/owadisp.show_document?p_table=STANDARDS\&p_id=9862 $>$ (Accessed January 11, 2013)

OSHA (1999). Procedures for Approval of Local Emphasis Programs (LEPs) Available at: <http://www.osha.gov/pls/oshaweb/owadisp.show_document?p_table=DIRECTIVES\&p_id=2252> (Accessed November 6, 2012)

OSHA (2011). OSHA Directive 2012-11(CPL 04) Logging in West Virginia. Available at: < www.osha.gov/dep/leps/RegionIII/logging_wv.doc > (Accessed October 4, 2012)

OSHA (2011). Accident: 200632354 - Logger Killed When Struck By Log <http://www.osha.gov/pls/imis/accidentsearch.accident_detail?id=200632354> (Accessed January $11,2013)$

Perezgonzalez, JD. (2011). The Iceberg Model. School of Aviation, Massey University (Available at http://www.aviation.massey.ac.nz)

Robotham, G. (2004). Why the Iceberg Theory has Misdirected Safety. Available at http://www.ohschange.com.au/articles/Iceberg_Theory/Iceberg_Theory.pdf

The Organisation for Economic Co-operation and Development 'OECD', (2008). Guidance on Developing Safety Performance Indicators related to Chemical Accident Prevention, Preparedness and Response for Industry (2008), 2nd ed., OECD Environment, Health and Safety Publications Series on Chemical Accidents, No. 19, Paris. (Accessed from http://www.oecd.org/ehs/)

West Virginia Department of Commerce, (2013). West Virginia Forests <http://www.wvcommerce.org/resources/forestry/default.aspx > (Accessed January 11, 2013)

West Virginia Forestry Association. Loggers Safety Initiative. Available at: http://www.wvfa.org/loggers.htm (accessed 26 November 2012). 


\section{APPENDICES}

\section{Appendix A: Sample Logging Inspection Database}

\begin{tabular}{|c|c|c|c|c|c|}
\hline SIC & NAICS & Date Range & Office & State & Other Options \\
\hline All & 113310 & $03 / 03 / 2008$ to $03 / 03 / 2013$ & All & WV & None \\
\hline
\end{tabular}

Please note that inspections which are known to be incomplete will have the identifying Activity Nr shown in italic. Information for these open cases is especially dynamic, e.g., violations may be added or deleted.

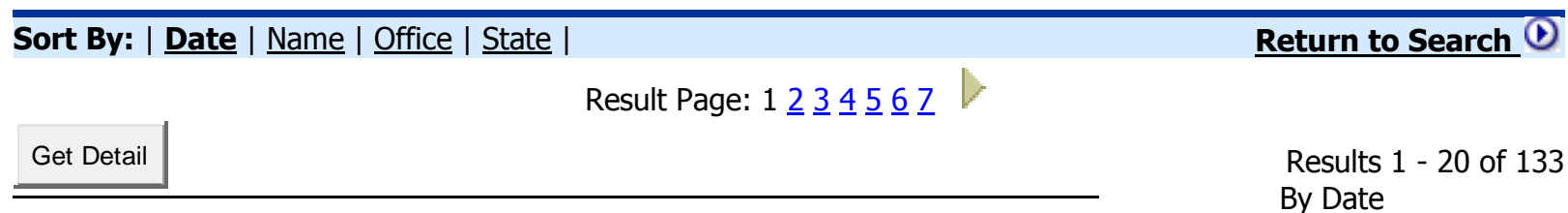

\begin{tabular}{|c|c|c|c|c|c|c|c|c|c|c|c|}
\hline & & Activity & Opened & RID & St & Type & Sc & SIC & NAICS & Vio & Establishment Name \\
\hline T & 1 & 891556.015 & $02 / 21 / 2013$ & 0316400 & WV & Accident & Complete & & 113310 & & Best Logging \\
\hline 厂 & 2 & 889464.015 & $02 / 06 / 2013$ & 0316400 & WV & Complaint & Complete & & 113310 & & Switchback Timber Llc \\
\hline$\Gamma$ & 3 & $\underline{57018.015}$ & $07 / 30 / 2012$ & 0316400 & WV & Complaint & Complete & & 113310 & 1 & Kincaid Logging Llc \\
\hline$\Gamma$ & 4 & $\underline{525518.015}$ & $07 / 11 / 2012$ & 0316400 & WV & Referral & Complete & & 113310 & & Cogar Enterprises, Llc \\
\hline$\Gamma$ & 5 & $\underline{510998.015}$ & $07 / 09 / 2012$ & 0316400 & WV & Referral & Complete & & 113310 & 1 & $\begin{array}{l}\text { Cogar Right-Away- } \\
\text { Clearing Llc }\end{array}$ \\
\hline$\Gamma$ & 6 & 454893.015 & $06 / 04 / 2012$ & 0316400 & WV & Accident & Complete & & 113310 & 8 & Backwoods Logging Llc \\
\hline$\Gamma$ & 7 & 315228312 & $04 / 12 / 2012$ & 0316400 & WV & Planned & Complete & 2411 & 113310 & & George Hunt Llc \\
\hline Г & 8 & $\underline{315228353}$ & $04 / 12 / 2012$ & 0316400 & WV & Planned & $\begin{array}{c}\text { No } \\
\text { Insp/Other }\end{array}$ & 2411 & 113310 & & John Ricottilli \\
\hline$\Gamma$ & 9 & $\underline{315228346}$ & $04 / 10 / 2012$ & 0316400 & WV & Planned & Complete & 2411 & 113310 & & Iron Horse Inc. \\
\hline$\Gamma$ & 10 & $\underline{315228320}$ & $04 / 10 / 2012$ & 0316400 & WV & Planned & Complete & 2411 & 113310 & 1 & Auvil Logging Llc \\
\hline Г & 11 & 315228338 & $04 / 09 / 2012$ & 0316400 & WV & Planned & Complete & 2411 & 113310 & 1 & Mountain Top Logging \\
\hline$\Gamma$ & 12 & $\underline{315228080}$ & $03 / 20 / 2012$ & 0316400 & WV & Accident & Complete & 2411 & 113310 & 5 & D \& K Logging, Inc. \\
\hline Г & 13 & $\underline{315227587}$ & $01 / 25 / 2012$ & 0316400 & WV & Planned & $\begin{array}{c}\text { No } \\
\text { Insp/Out } \\
\text { of } \\
\text { Business }\end{array}$ & 2411 & 113310 & & $\begin{array}{l}\text { Mountaineer Timber } \\
\text { Frames Llc }\end{array}$ \\
\hline$\Gamma$ & 14 & 315226837 & $11 / 15 / 2011$ & 0316400 & WV & Accident & Complete & 2411 & 113310 & 8 & Parsons Logging \\
\hline$\Gamma$ & 15 & $\underline{315226795}$ & $11 / 09 / 2011$ & 0316400 & WV & Planned & Complete & 2411 & 113310 & 6 & Noah Perkins \\
\hline$\Gamma$ & 16 & 315226787 & $11 / 08 / 2011$ & 0316400 & WV & Prog Related & Partial & 2411 & 113310 & 1 & $\begin{array}{l}\text { Rickey C. Trucking, } \\
\text { Inc. }\end{array}$ \\
\hline$\Gamma$ & 17 & 315226779 & $11 / 08 / 2011$ & 0316400 & WV & Planned & Complete & 2411 & 113310 & 4 & T \& R Logging \\
\hline$\Gamma$ & 18 & 315226696 & $11 / 03 / 2011$ & 0316400 & WV & Planned & Complete & 2411 & 113310 & 4 & Calhoun Logging \\
\hline$\Gamma$ & 19 & $\underline{315226688}$ & $11 / 02 / 2011$ & 0316400 & WV & Planned & Complete & 2411 & 113310 & 2 & Kat Contracting \\
\hline$\Gamma$ & 20 & 315226217 & $09 / 01 / 2011$ & 0316400 & WV & Planned & Partial & 2411 & 113310 & 2 & Mill Run Logging \\
\hline
\end{tabular}

(OSHA, 2012) 


\section{Appendix B: Sample Inspection Summary}

Inspection: 454893.015 - Backwoods Logging Llc

\begin{tabular}{|c|c|c|}
\hline \multicolumn{3}{|c|}{ Inspection Information - Office: Charleston } \\
\hline $\mathrm{Nr}: 454893.015$ & Report ID:0316400 & Open Date: 06/04/2012 \\
\hline $\begin{array}{l}\text { Backwoods Logging Llc } \\
\text { Route } 19 \text { dawson Hollow Road } \\
\text { Worthington, WV } 26591 \\
\text { SIC: } \\
\text { NAICS: } 113310 / \text { Logging } \\
\text { Mailing: } 609 \text { Feather Road, Terra Alta, WV }\end{array}$ & 26764 & Union Status: NonUnion \\
\hline $\begin{array}{c}\text { Inspection Type: Accident } \\
\text { Scope: Complete } \\
\text { Ownership: Private } \\
\text { Safety/Health: Safety } \\
\text { Emphasis: L:Logging }\end{array}$ & & $\begin{array}{l}\text { Advanced Notice: } N \\
\text { Close Conference: 06/05/2012 } \\
\text { Close Case: }\end{array}$ \\
\hline $\begin{array}{l}\text { Optional Information: Type } \\
\mathrm{N}\end{array}$ & $\begin{array}{ll}\text { ID } & \text { Value } \\
10 & \text { IMMLANG-N }\end{array}$ & \\
\hline $\begin{array}{r}\text { Related Activity: Type } \\
\text { Accident }\end{array}$ & $\begin{array}{l}\text { ID } \\
379069\end{array}$ & Health \\
\hline
\end{tabular}

\begin{tabular}{|c|c|c|c|c|c|c|}
\hline & \multicolumn{6}{|c|}{ Violation Summary } \\
\hline & Serious & Willful & Repeat & Other & Unclass & Total \\
\hline Initial Violations & 4 & & & 4 & & 8 \\
\hline Current Violations & 4 & & & 4 & & 8 \\
\hline Initial Penalty & 12600 & & & & & 12600 \\
\hline Current Penalty & 6300 & & & & & 6300 \\
\hline FTA Amount & & & & & & \\
\hline
\end{tabular}

\begin{tabular}{|c|c|c|c|c|c|c|c|c|}
\hline \multicolumn{9}{|c|}{ Violation Items } \\
\hline ID & Type & Standard & Issuance & Abate & Curr\$ & Init\$ & Fta\$ Contest & LastEvent \\
\hline 1. 01001 & Serious & 19100266 D01 VII B & $12 / 03 / 2012$ & 09/30/2012 & $\$ 1000$ & $\$ 2000$ & $\$ 0$ & I - Informal Settlement \\
\hline 2. $\underline{01002}$ & Serious & 19100266 H01 VI & $12 / 03 / 2012$ & 09/30/2012 & $\$ 3500$ & $\$ 7000$ & $\$ 0$ & I - Informal Settlement \\
\hline 3. 01003 & Serious & 19100266 H08 & $12 / 03 / 2012$ & 09/30/2012 & $\$ 800$ & $\$ 1600$ & $\$ 0$ & I - Informal Settlement \\
\hline 4. 01004 & Serious & 19100266 I07 I & $12 / 03 / 2012$ & 09/30/2012 & $\$ 1000$ & $\$ 2000$ & $\$ 0$ & I - Informal Settlement \\
\hline 5. $\underline{02001}$ & Other & 19100266 G03 & $12 / 03 / 2012$ & 09/30/2012 & $\$ 0$ & $\$ 0$ & $\$ 0$ & I - Informal Settlement \\
\hline $6 . \underline{02002}$ & Other & 19100266 D04 & $12 / 03 / 2012$ & 09/30/2012 & $\$ 0$ & $\$ 0$ & $\$ 0$ & I - Informal Settlement \\
\hline 7. $\underline{02003}$ & Other & 19100266 I10 & $12 / 03 / 2012$ & $09 / 30 / 2012$ & $\$ 0$ & $\$ 0$ & $\$ 0$ & I - Informal Settlement \\
\hline 8. $\underline{02004}$ & Other & 19101200 E01 & $12 / 03 / 2012$ & 09/30/2012 & $\$ 0$ & $\$ 0$ & $\$ 0$ & I - Informal Settlement \\
\hline
\end{tabular}

(OSHA, 2012) 


\title{
Appendix C: Sample Inspection and Incident Investigation Summary
}

\author{
Inspection: 315224386 - Back Country Logging
}

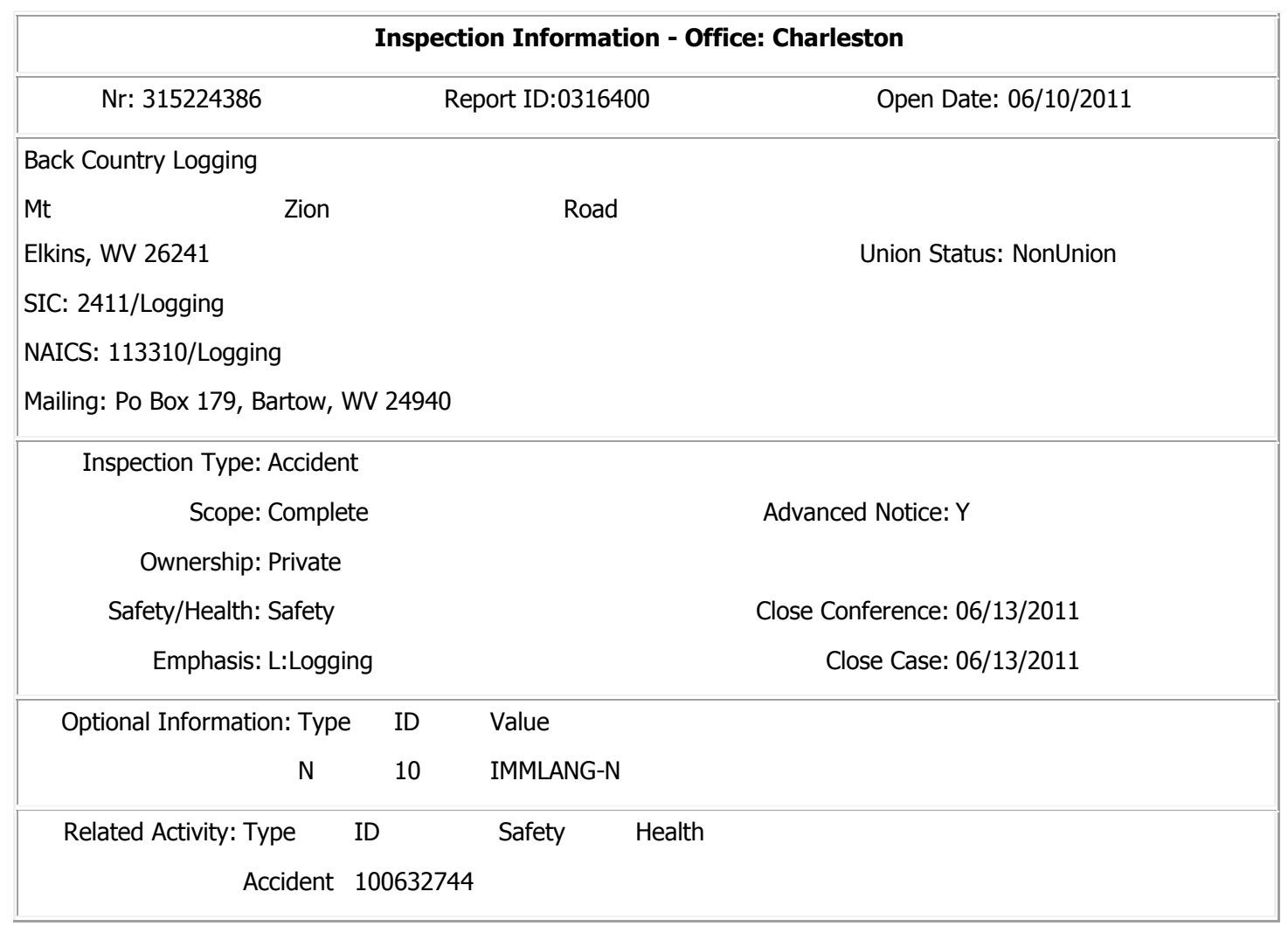

\section{Accident Investigation Summary}

Summary Nr: 200632354 Event: 06/08/2011 Logger Killed When Struck By Log

On June 8, 2011, Employee \#1, a 21-year-old male, was working alongside skidder operator with Back Country Logging who was moving a load of logs at the landing area, when the tire of the skidder made contact with a log on the ground. The log on the ground struck Employee \#1 on the back of the head and shoulder. Employee \#1 was killed in the event.

\begin{tabular}{|c|c|c|c|}
\hline Keywords: & \multicolumn{3}{|c|}{ log, skidder, logger, struck by, head, shoulder } \\
\hline Inspection & Degree & Nature & Occupation \\
\hline$\underline{315224386}$ & Fatality & Other & Occupation not reported \\
\hline
\end{tabular}

(OSHA, 2011) 


\section{Appendix D: Derived Variables}

\begin{tabular}{|c|c|c|c|c|c|c|}
\hline & YEAR & Fatality/T.L Rate & Loggers Trained/T.L & $\begin{array}{l}\text { Rate of Complaint } \\
\text { and Acident } \\
\text { Inspection/T.L }\end{array}$ & $\begin{array}{l}\text { Rate of complaint } \\
\text { and accident } \\
\text { ins/insp }\end{array}$ & Total Violations/T.L \\
\hline 1 & 2003 & 0.003053435 & 0.984732824 & 0.003816794 & 0.096153846 & 0.22519084 \\
\hline 2 & 2004 & 0.003455425 & 0.891499654 & 0.00691085 & 0.126582278 & 0.322736697 \\
\hline 3 & 2005 & 0.001370802 & 1.037011652 & 0.004797807 & 0.074468085 & 0.318711446 \\
\hline 4 & 2006 & 0.000734754 & 0.957384276 & 0.001469508 & 0.016666667 & 0.388684791 \\
\hline 5 & 2007 & 0.004058442 & 1.051136364 & 0.006493506 & 0.1066666667 & 0.278409091 \\
\hline 6 & 2008 & 0 & 1.079564489 & 0.005025126 & 0.101694915 & 0.182579564 \\
\hline 7 & 2009 & 0.000994036 & 0.824055666 & 0.000994036 & 0.041666667 & 0.086481113 \\
\hline 8 & 2010 & 0.003112033 & 1.043568465 & 0.005186722 & 0.128205128 & 0.073651452 \\
\hline 9 & 2011 & 0.001113586 & 1.18596882 & 0.003340757 & 0.142857143 & 0.069042316 \\
\hline 10 & 2012 & 0 & 0.687014428 & 0.003329634 & 0.272727273 & 0.018867925 \\
\hline
\end{tabular}

\begin{tabular}{|r|r|r|r|}
\hline & & & \\
& Cost of Violations/T.L & Repeated violations/T.L & Reapeted violations/Inspections \\
\hline 1 & 70.67938931 & 0.009923664 & 0.25 \\
\hline 2 & 111.4132688 & 0.02211472 & 0.405063291 \\
\hline 3 & 87.55997258 & 0.018505826 & 0.287234043 \\
\hline 4 & 156.9360764 & 0.020573108 & 0.233333333 \\
\hline 5 & 93.99756494 & 0.010551948 & 0.173333333 \\
\hline 6 & 98.00670017 & 0.001675042 & 0.033898305 \\
\hline 7 & 46.88369781 & 0.005964215 & 0.25 \\
\hline 8 & 57.48443983 & 0 & 0 \\
\hline 9 & 96.46714922 & 0.006681514 & 0.285714286 \\
\hline 10 & 9.589345172 & 0 & 0 \\
\hline
\end{tabular}

\begin{tabular}{|r|r|r|r|}
\hline & $\begin{array}{c}\text { Planned Inspection/Logging } \\
\text { Operations }\end{array}$ & Total Inspections/Logging Operations & Certified Loggers/T.L \\
\hline 1 & 0.012876793 & 0.015218028 & 1.178299931 \\
\hline 2 & 0.017647059 & 0.022128852 & 1.202193283 \\
\hline 3 & 0.021258503 & 0.026643991 & 1.252020573 \\
\hline 4 & 0.033323143 & 0.036686029 & 1.320616883 \\
\hline 5 & 0.020665499 & 0.026269702 & 1.341708543 \\
\hline 6 & 0.020537125 & 0.023301738 & 1.388667992 \\
\hline 7 & 0.010859301 & 0.011331445 & 1.358921162 \\
\hline 8 & 0.014425314 & 0.018147976 & 1.322939866 \\
\hline 9 & 0.00798005 & 0.010473815 & 1.31409545 \\
\hline 10 & 0.003237992 & 0.005936319 & 1.314 \\
\hline
\end{tabular}




\begin{tabular}{|c|c|c|c|c|c|c|c|c|c|c|}
\hline & YEAR & Timber & Logging & Trained & Certified & Total inspections & Planned inspection & Total violation & Repeated violations(Current) & Cost of violations \\
\hline 1 & 2008 & 1381 & 3271 & 1303 & 1704 & 120 & 100 & 528 & 28 & 341625 \\
\hline 2 & 2007 & 1232 & 2855 & 1295 & 1627 & 75 & 50 & 343 & 13 & 241675 \\
\hline 3 & 2008 & 1184 & 2532 & 1288 & 1602 & 50 & 52 & 218 & 2 & 168725 \\
\hline 4 & 2000 & 1008 & 2118 & 829 & 1397 & 24 & 23 & 87 & 6 & 77425 \\
\hline 5 & 2010 & 884 & 2148 & 1006 & 1310 & 30 & 31 & 71 & 0 & 78400 \\
\hline
\end{tabular}

JMP_DATA[2]

\begin{tabular}{|c|c|c|c|c|c|c|c|c|c|}
\hline & $\begin{array}{l}\text { Number of } \\
\text { fatalities }\end{array}$ & FatalityIT.L Rate & $\begin{array}{c}\text { Number of } \\
\text { claims }\end{array}$ & $\begin{array}{l}\text { Cost of } \\
\text { Claims }\end{array}$ & Medical cost & Payroll & Loggers Trained/T.L & Total Inspections $/ \mathrm{TL}$ & Pld Inspections/T.L \\
\hline 1 & 1 & 0.000734754 & 0 & 0 & 0 & 0 & 0.857394276 & 0.088170463 & 0.08008817 \\
\hline 2 & 5 & 0.004058442 & 88 & 3346302 & 2386729 & 17682234 & 1.051136364 & 0.080876623 & 0.04788961 \\
\hline 3 & 0 & 0 & 60 & 1038462 & 2091108 & 18009761 & 1.070584488 & 0.042413735 & 0.043551089 \\
\hline 4 & 1 & 0.000294036 & 43 & 1070408 & 1899104 & 11797352 & 0.824055686 & 0.023858850 & 0.022862823 \\
\hline 5 & 3 & 0.003112033 & 37 & 744203 & 1943247 & 10551873 & 1.043568465 & 0.040456432 & 0.032157676 \\
\hline
\end{tabular}

JMP_DATA[2]

\begin{tabular}{|c|c|c|c|c|c|c|}
\hline & $\begin{array}{l}\text { Rate of Complaint } \\
\text { and Acident } \\
\text { Inspection }\end{array}$ & $\begin{array}{c}\text { Rate of complaint } \\
\text { and accident } \\
\text { ins/insp }\end{array}$ & Total Violations $T$ T.L & Cost of Violations $/$ T.L & Repeated violations/T.L & Reapeted violations/Inspections \\
\hline 1 & 0.001480508 & 0.018808687 & 0.388684791 & 251.0102868 & 0.020573108 & 0.233333332 \\
\hline 2 & 0.006482506 & 0.108886867 & 0.278400091 & 198.1847727 & 0.010551848 & 0.173333333 \\
\hline 3 & 0.005025126 & 0.101004815 & 0.182578564 & 142.1482412 & 0.001875042 & 0.033988305 \\
\hline 4 & 0.000924036 & 0.041888687 & 0.086481113 & 76.96322068 & 0.005964215 & 0.25 \\
\hline 5 & 0.005188722 & 0.128205128 & 0.073651452 & 79.25311203 & 0 & 0 \\
\hline
\end{tabular}

\begin{tabular}{|c|c|c|c|c|c|c|c|c|}
\hline & $\begin{array}{c}\text { Planned Inspection/Logging } \\
\text { Operations }\end{array}$ & $\begin{array}{l}\text { Number of } \\
\text { claims } / T . L\end{array}$ & Cost $T$.L & Medical Cost T.L & Payroll/T.L & Total Inspections/Logging Operations & Column 9 & Column 10 \\
\hline 1 & 0.033323 & 0 & 0 & 0 & 0 & $0.03689602 \theta$ & & \\
\hline 2 & 0.020885 & 0.071429 & 2716.15422 & 1837.28003 & 14352.4627 & 0.026260702 & & \\
\hline 3 & 0.020537 & 0.057788 & 869.733688 & 1751.34506 & 13408.5101 & 0.023301738 & & \\
\hline 4 & 0.010859 & 0.042744 & 1064.02386 & 1877.77734 & 11726.9901 & 0.011331445 & & \\
\hline 5 & 0.014425 & 0.038382 & 771.994813 & 2015.81639 & 10045.7180 & 0.018147976 & & \\
\hline
\end{tabular}




\section{Appendix E: JMP SAS Data Analysis Reports}

Fit $Y$ by $X$ Group

Bivariate Fit of Medical Cost/T.L By Total Inspections/Logging Operations

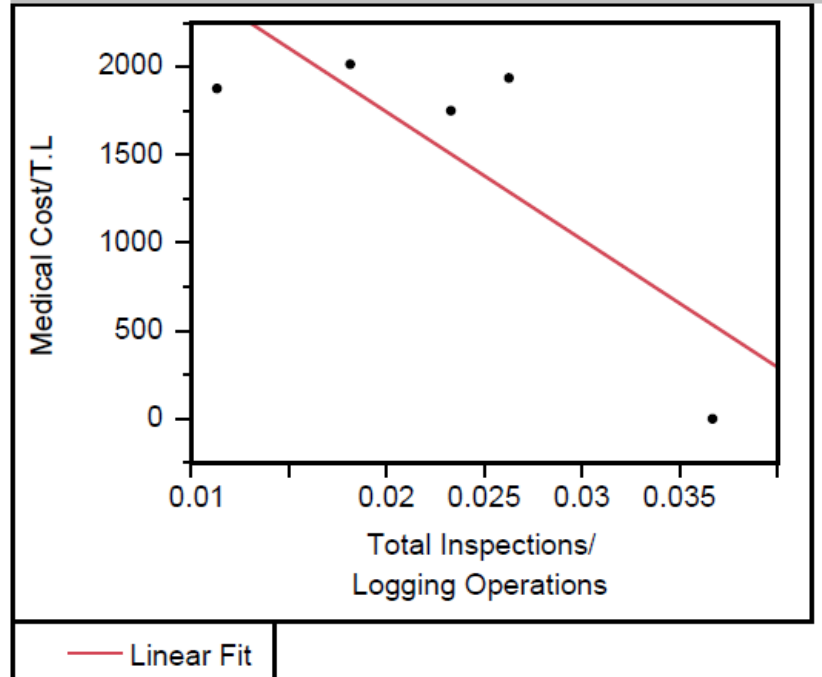

Linear Fit

Medical Cost/T.L = $3195.5834-72541.244 *$ Total Inspections/Logging Operations

\begin{tabular}{|c|c|c|c|c|}
\hline \multicolumn{4}{|c|}{ Summary of Fit } & \\
\hline \multicolumn{3}{|c|}{ RSquare } & 0.646395 & \\
\hline \multicolumn{3}{|c|}{ RSquare Adj } & 0.528527 & \\
\hline \multicolumn{3}{|c|}{ Root Mean Square Error } & 585.8422 & \\
\hline \multicolumn{3}{|c|}{ Mean of Response } & 1516.444 & \\
\hline \multicolumn{3}{|c|}{ Observations (or Sum Wgts) } & 5 & \\
\hline \multicolumn{5}{|c|}{ Analysis of Variance } \\
\hline \multicolumn{5}{|c|}{ Sum of } \\
\hline Model & 1 & 1882185.2 & 1882185 & 5.4840 \\
\hline Error & 3 & 1029633.3 & 343211 & Prob $>F$ \\
\hline C. Total & 4 & 2911818.4 & & 0.1011 \\
\hline
\end{tabular}

\begin{tabular}{|lrrrr|}
\hline Parameter Estimates & & & & \\
\hline Term & Estimate & Std Error & t Ratio & Prob $>|t|$ \\
Intercept & 3195.5834 & 763.3949 & 4.19 & 0.0249 * \\
Total Inspections/Logging Operations & -72541.24 & 30976.65 & -2.34 & 0.1011
\end{tabular}




\section{Fit $Y$ by $X$ Group}

\section{Bivariate Fit of Medical Cost/T.L By Planned Inspection/Logging Operations}

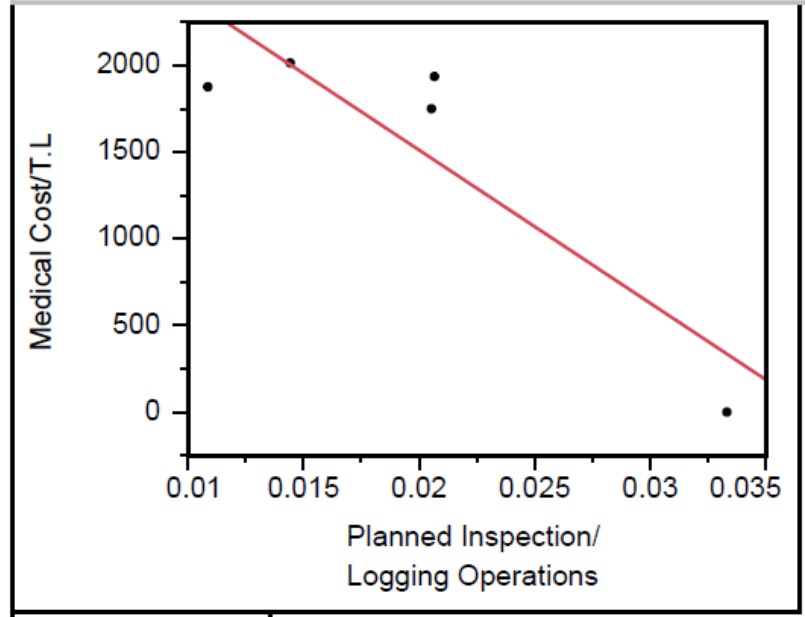

_ Linear Fit

\section{Linear Fit}

Medical Cost $/ \mathrm{T} . \mathrm{L}=3280.7496-88384.107^{\star}$ Planned

Inspection/Logging Operations

\begin{tabular}{lr}
\hline Summary of Fit & \\
\hline RSquare & 0.785688 \\
RSquare Adj & 0.714251 \\
Root Mean Square Error & 456.0837 \\
Mean of Response & 1516.444 \\
Observations (or Sum Wgts) & 5
\end{tabular}

\begin{tabular}{|lr|r|r|r|}
\hline \multicolumn{5}{|l}{ Analysis of Variance } \\
\hline & \multicolumn{5}{c|}{ Sum of } & & \\
Source & DF & Squares & Mean Square & F Ratio \\
Model & 1 & 2287781.5 & 2287781 & 10.9983 \\
Error & 3 & 624037.0 & 208012 & Prob > F \\
C. Total & 4 & 2911818.4 & & 0.0452 *
\end{tabular}

\begin{tabular}{|lrrrr|}
\hline Parameter Estimates & & & & \\
\hline Term & Estimate & Std Error & t Ratio & Prob $>|\mathrm{t}|$ \\
Intercept & 3280.7496 & 569.7594 & 5.76 & 0.0104 * \\
Planned Inspection/Logging Operations & -88384.11 & 26650.87 & -3.32 & 0.0452 *
\end{tabular}




\section{Fit $Y$ by $X$ Group}

Bivariate Fit of Total Violations/T.L By Total Inspections/Logging Operations

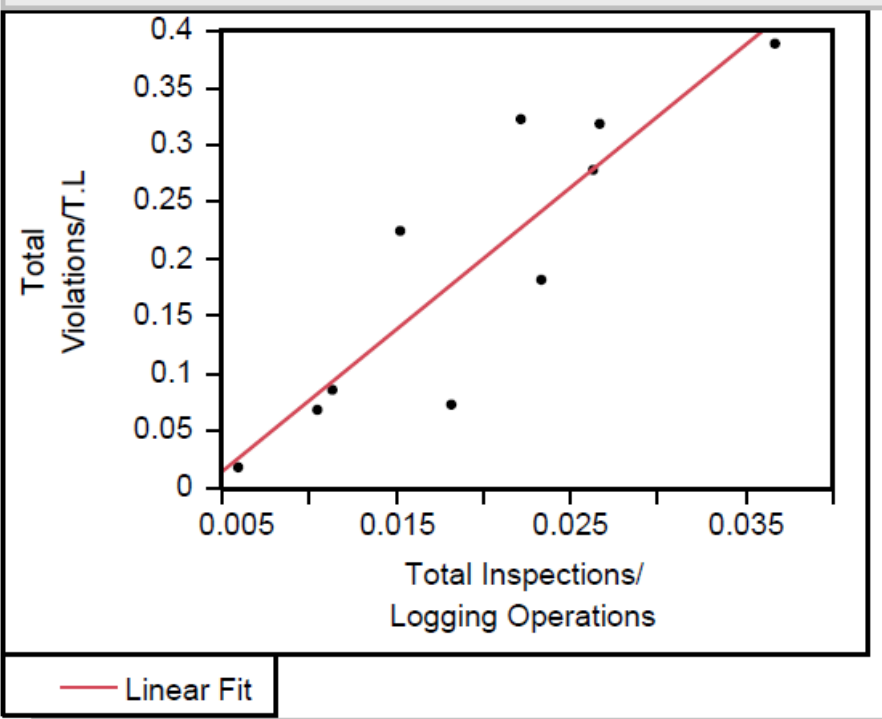

\section{Linear Fit}

Total Violations $/$ T.L $=-0.047169+12.420079 *$ Total

Inspections/Logging Operations

\begin{tabular}{|c|c|c|c|c|}
\hline \multicolumn{4}{|c|}{ Summary of Fit } & \\
\hline \multicolumn{3}{|c|}{ RSquare } & \multicolumn{2}{|l|}{0.784777} \\
\hline \multicolumn{3}{|c|}{ RSquare Adj } & \multicolumn{2}{|l|}{0.757874} \\
\hline \multicolumn{3}{|c|}{ Root Mean Square Error } & \multicolumn{2}{|l|}{0.063636} \\
\hline \multicolumn{3}{|c|}{ Mean of Response } & \multicolumn{2}{|l|}{0.196436} \\
\hline \multicolumn{3}{|c|}{ Observations (or Sum Wgts) } & 10 & \\
\hline \multicolumn{5}{|c|}{ Analysis of Variance } \\
\hline \multicolumn{4}{|c|}{ Sum of } & F Ratio \\
\hline Model & 1 & 0.11813007 & 0.118130 & 29.1708 \\
\hline Error & 8 & 0.03239680 & 0.004050 & Prob $>F$ \\
\hline C. Total & 9 & 0.15052687 & & 0.0006 * \\
\hline
\end{tabular}

\begin{tabular}{lrrrrr}
\hline Parameter Estimates & & & & \\
\hline Term & Estimate & Std Error & t Ratio & Prob $>|\mathbf{t}|$ \\
Intercept & -0.047169 & 0.049389 & -0.96 & 0.3675 \\
Total Inspections/Logging Operations & 12.420079 & 2.299589 & 5.40 & 0.0006 *
\end{tabular}




\section{Fit $Y$ by $X$ Group}

\section{Bivariate Fit of Total Violations/T.L By Planned Inspection/Logging Operations}

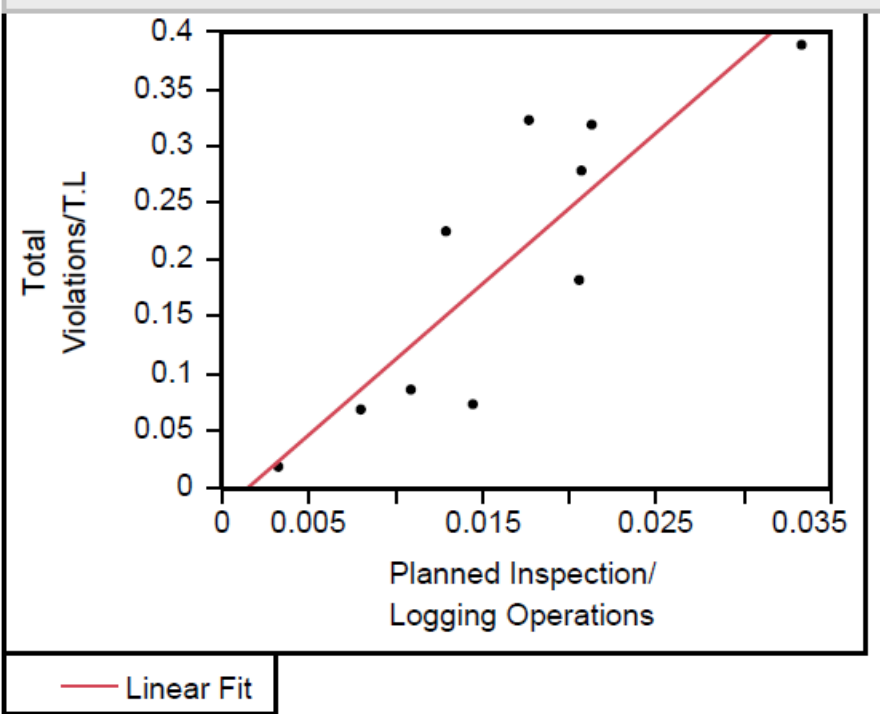

\section{Linear Fit}

Total Violations $/ \mathrm{T} . \mathrm{L}=-0.019437+13.259089^{*}$ Planned Inspection/Logging Operations

\begin{tabular}{lr}
\hline Summary of Fit & \\
\hline RSquare & 0.744979 \\
RSquare Adj & 0.713101 \\
Root Mean Square Error & 0.069271 \\
Mean of Response & 0.196436 \\
Observations (or Sum Wgts) & 10
\end{tabular}

Observations (or Sum Wgts) $\quad 10$

\begin{tabular}{|lr|r|r|r|}
\hline \multicolumn{4}{l}{ Analysis of Variance } \\
\hline Source & DF & $\begin{array}{r}\text { Sum of } \\
\text { Squares }\end{array}$ & Mean Square & F Ratio \\
Model & 1 & 0.11213932 & 0.112139 & 23.3699 \\
Error & 8 & 0.03838755 & 0.004798 & Prob > F \\
C. Total & 9 & 0.15052687 & & 0.0013 *
\end{tabular}

\section{Parameter Estimates}

$\begin{array}{lrrrl}\text { Term } & \text { Estimate } & \text { Std Error } & \text { t Ratio } & \text { Prob }>|t| \\ \text { Intercept } & -0.019437 & 0.049738 & -0.39 & 0.7062 \\ \text { Planned Inspection/Logging Operations } & 13.259089 & 2.742742 & 4.83 & 0.0013 \text { * }\end{array}$




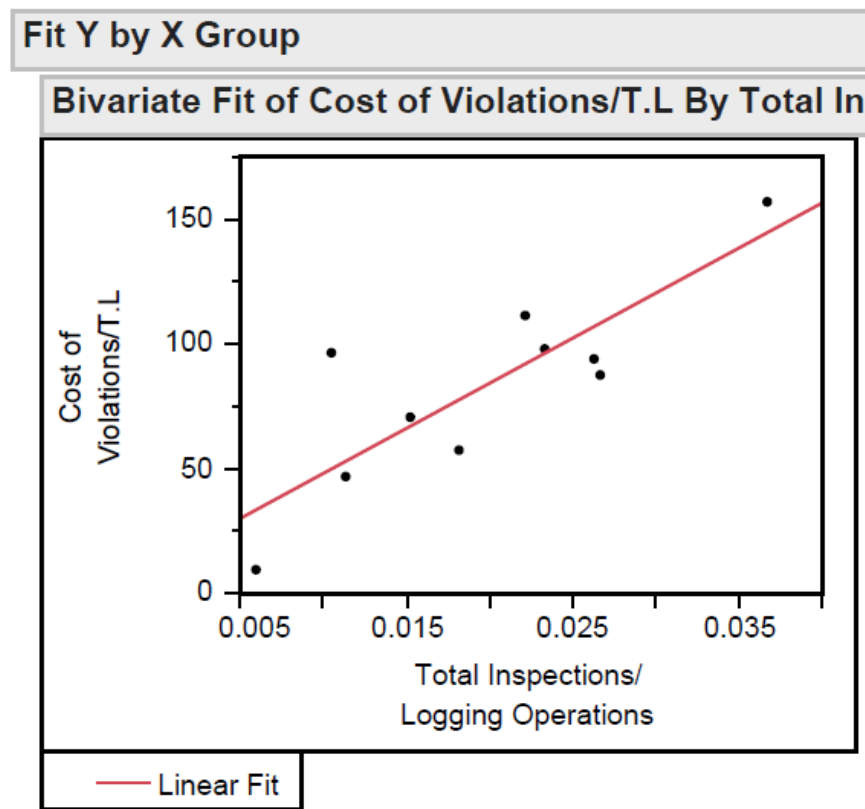
Linear Fit
Cost of Violations/T.L $=12.058316+3611.9203^{\star}$ Total
Inspections/Logging Operations

\begin{tabular}{|c|c|c|c|c|}
\hline \multicolumn{4}{|c|}{ Summary of Fit } & \\
\hline \multicolumn{3}{|l|}{ RSquare } & \multicolumn{2}{|c|}{0.697739} \\
\hline \multicolumn{3}{|c|}{ RSquare Adj } & \multicolumn{2}{|c|}{0.659956} \\
\hline \multicolumn{3}{|c|}{ Root Mean Square Error } & \multicolumn{2}{|c|}{23.25913} \\
\hline \multicolumn{3}{|c|}{ Mean of Response } & \multicolumn{2}{|c|}{82.90176} \\
\hline \multicolumn{3}{|c|}{ Observations (or Sum Wgts) } & \multicolumn{2}{|l|}{10} \\
\hline \multicolumn{5}{|c|}{ Analysis of Variance } \\
\hline \multicolumn{5}{|c|}{ Sum of } \\
\hline Model & 1 & 9990.520 & 9990.52 & 18.4672 \\
\hline Error & 8 & 4327.899 & 540.99 & Prob $>$ F \\
\hline C. Total & 9 & 14318.418 & & 0.0026 * \\
\hline
\end{tabular}

\begin{tabular}{lrrrr|}
\hline Parameter Estimates & & & & \\
\hline Term & Estimate & Std Error & t Ratio & Prob $>|\mathbf{t}|$ \\
Intercept & 12.058316 & 18.05178 & 0.67 & 0.5229 \\
Total Inspections/Logging Operations & 3611.9203 & 840.4999 & 4.30 & 0.0026 *
\end{tabular}


Fit $\mathrm{Y}$ by $\mathrm{X}$ Group

Bivariate Fit of Cost of Violations/T.L By Planned Inspection/Logging Operations

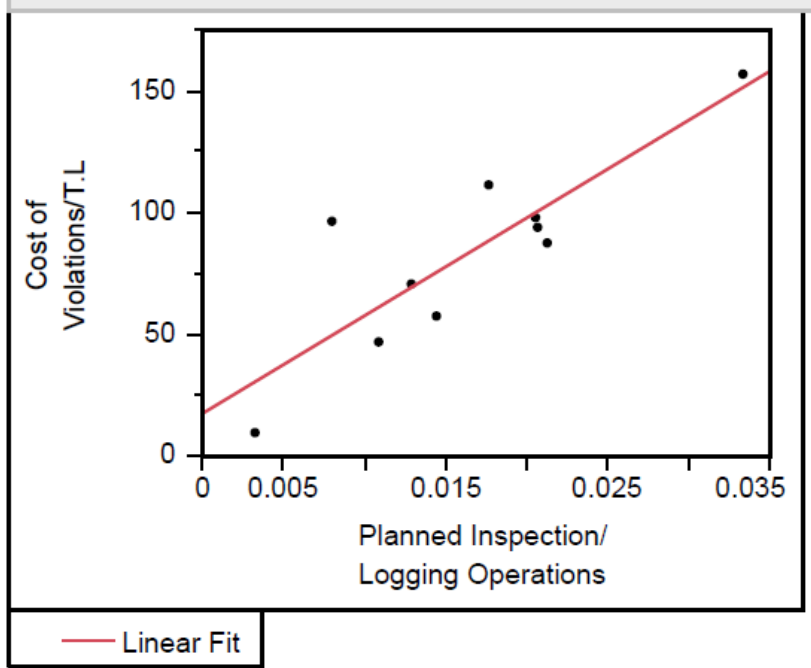

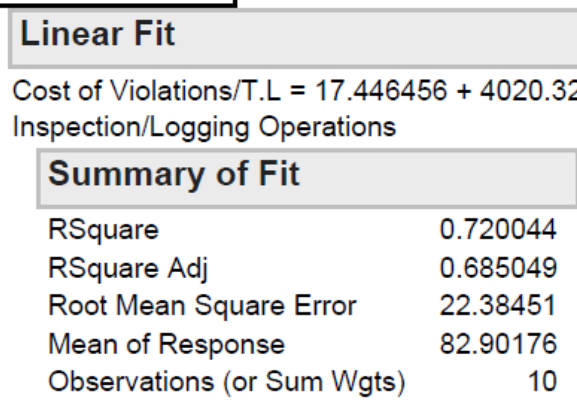

Analysis of Variance

\begin{tabular}{|lr|r|r|r|}
\hline Source & DF & $\begin{array}{r}\text { Sum of } \\
\text { Squares }\end{array}$ & Mean Square & F Ratio \\
Model & 1 & 10309.887 & 10309.9 & 20.5759 \\
Error & 8 & 4008.531 & 501.1 & Prob > F \\
C. Total & 9 & 14318.418 & & 0.0019 *
\end{tabular}

\begin{tabular}{|lrrrr|}
\hline Parameter Estimates & & & & \\
\hline Term & Estimate & Std Error & t Ratio & Prob $>|\mathrm{t}|$ \\
Intercept & 17.446456 & 16.07267 & 1.09 & 0.3093 \\
Planned Inspection/Logging Operations & 4020.3299 & 886.3033 & 4.54 & 0.0019 *
\end{tabular}




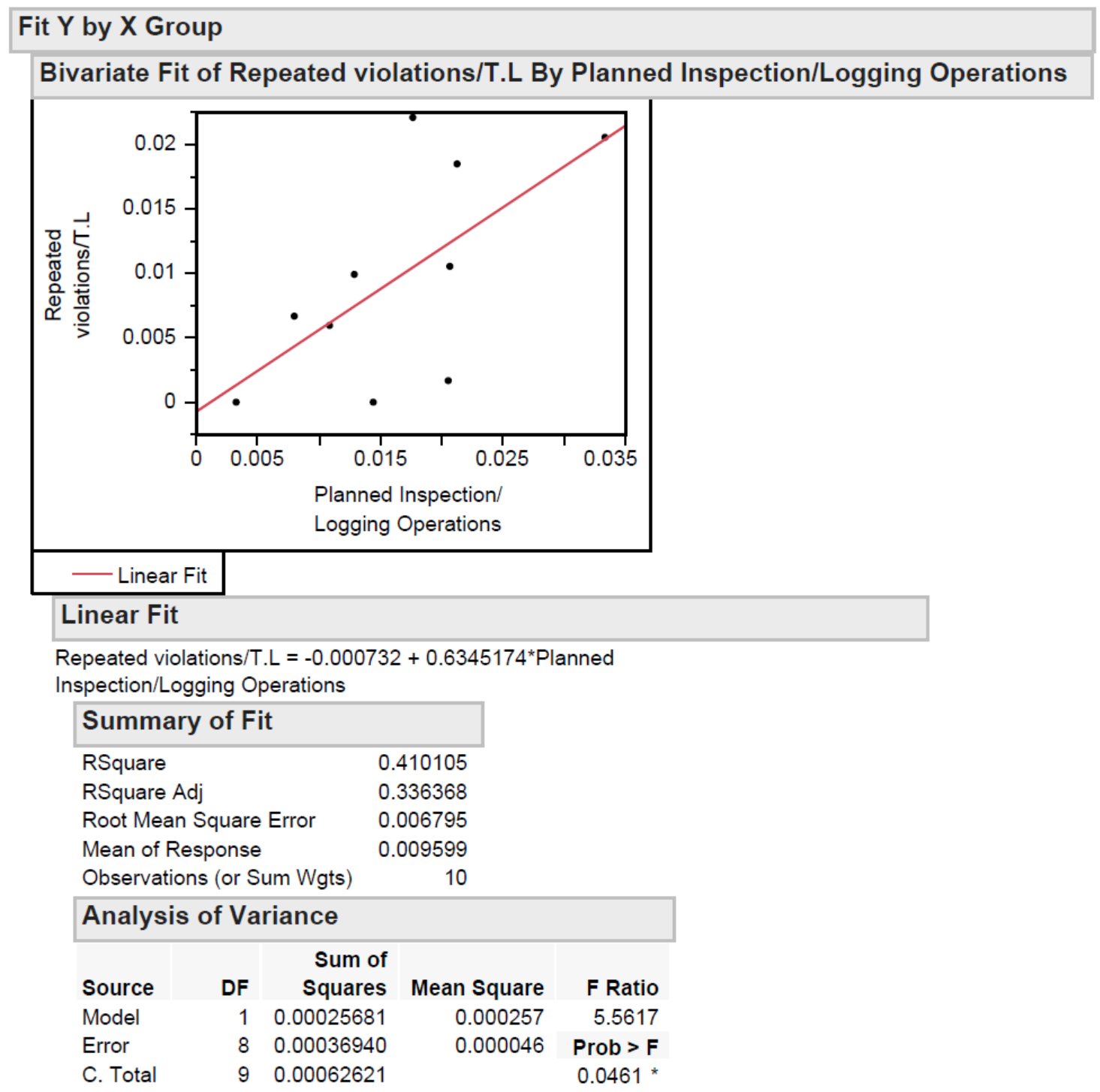

\begin{tabular}{|lrrrr|}
\hline Parameter Estimates & & & & \\
\hline Term & Estimate & Std Error & t Ratio & Prob $>|\mathrm{t}|$ \\
Intercept & -0.000732 & 0.004879 & -0.15 & 0.8845 \\
Planned Inspection/Logging Operations & 0.6345174 & 0.269053 & 2.36 & 0.0461 *
\end{tabular}


JMP_DATA[2] - Fit $Y$ by $X$ of Rate of complaint and accident ins/insp

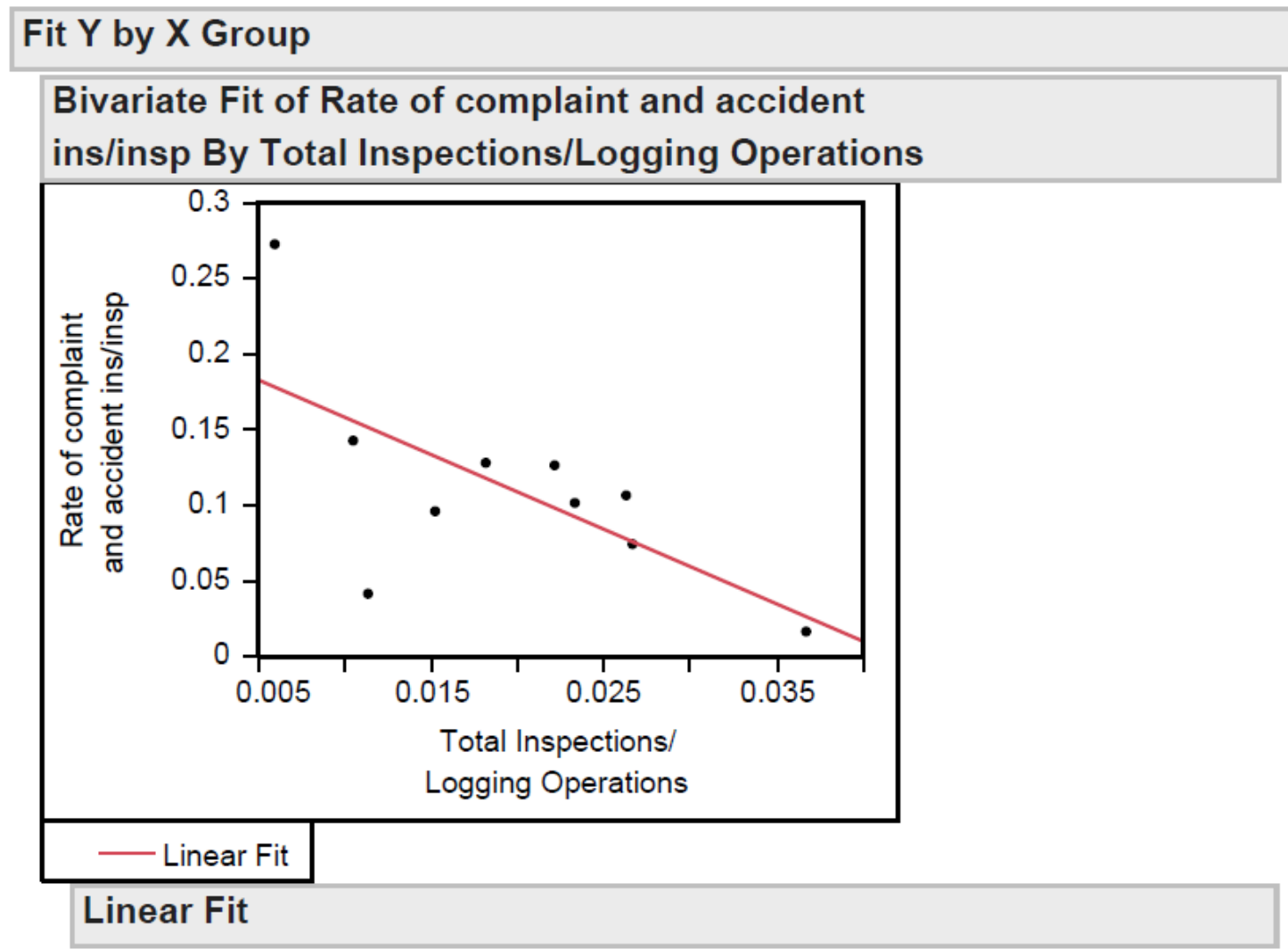

Rate of complaint and accident ins/insp $=0.2075884$ -

4.9362994*Total Inspections/Logging Operations

\begin{tabular}{lr} 
Summary of Fit & \\
\hline RSquare & 0.4332 \\
RSquare Adj & 0.36235 \\
Root Mean Square Error & 0.055244 \\
Mean of Response & 0.110769 \\
Observations (or Sum Wgts) & 10
\end{tabular}

\begin{tabular}{|c|c|c|c|c|}
\hline \multicolumn{5}{|c|}{ Analysis of Variance } \\
\hline Source & DF & $\begin{array}{r}\text { Sum of } \\
\text { Squares }\end{array}$ & Mean Square & F Ratio \\
\hline Model & 1 & 0.01866013 & 0.018660 & 6.1143 \\
\hline Error & 8 & 0.02441498 & 0.003052 & Prob $>$ F \\
\hline C. Total & 9 & 0.04307512 & & 0.0385 * \\
\hline
\end{tabular}

\begin{tabular}{|lrrrr|}
\hline Parameter Estimates & & & & \\
\hline Term & Estimate & Std Error & t Ratio & Prob $>|t|$ \\
Intercept & 0.2075884 & 0.042876 & 4.84 & $0.0013^{*}$ \\
Total Inspections/Logging Operations & -4.936299 & 1.996307 & -2.47 & 0.0385 *
\end{tabular}




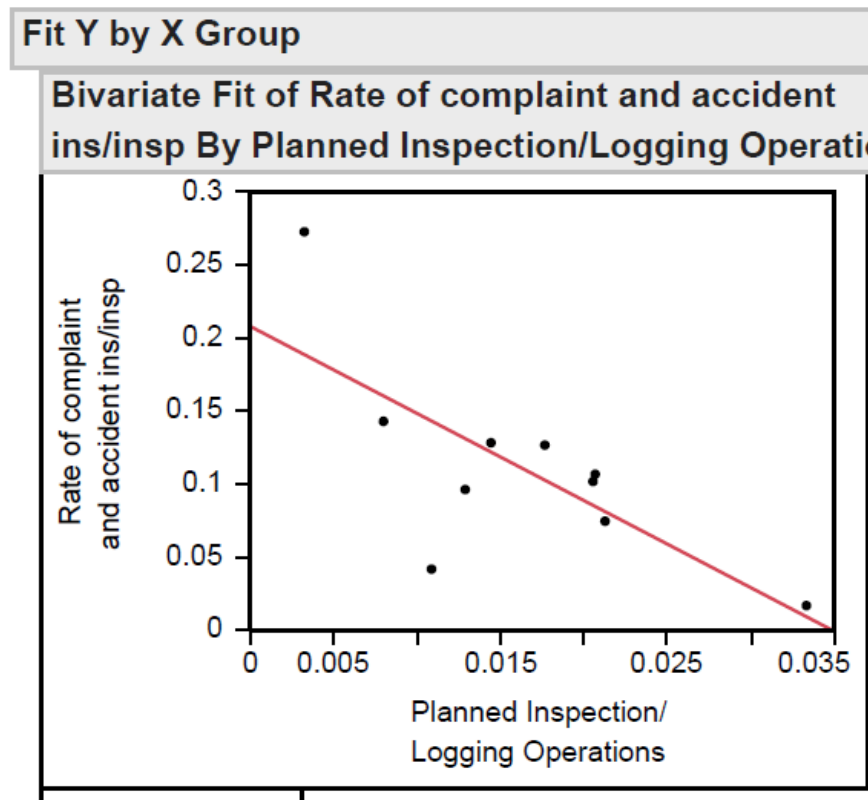

- Linear Fit

Linear Fit

Rate of complaint and accident ins/insp $=0.2079175$ -

5.9669668*Planned Inspection/Logging Operations

\begin{tabular}{lr}
\hline Summary of Fit & \\
\hline RSquare & 0.527244 \\
RSquare Adj & 0.468149 \\
Root Mean Square Error & 0.050453 \\
Mean of Response & 0.110769 \\
Observations (or Sum Wgts) & 10
\end{tabular}

\begin{tabular}{|l|r|r|r|r|}
\hline \multicolumn{4}{|c|}{ Analysis of Variance } \\
\hline Source & DF & $\begin{array}{r}\text { Sum of } \\
\text { Squares }\end{array}$ & Mean Square & F Ratio \\
Model & 1 & 0.02271108 & 0.022711 & 8.9220 \\
Error & 8 & 0.02036404 & 0.002546 & Prob > F \\
C. Total & 9 & 0.04307512 & & 0.0174 *
\end{tabular}

\begin{tabular}{|lrrrr|}
\hline Parameter Estimates & & & & \\
\hline Term & Estimate & Std Error & t Ratio & Prob $>|\mathrm{t}|$ \\
Intercept & 0.2079175 & 0.036227 & 5.74 & $0.0004^{*}$ \\
Planned Inspection/Logging Operations & -5.966967 & 1.997661 & -2.99 & 0.0174 *
\end{tabular}


Fit $\mathrm{Y}$ by $\mathrm{X}$ Group

Bivariate Fit of Repeated violations/T.L By Total Inspections/Logging Operations

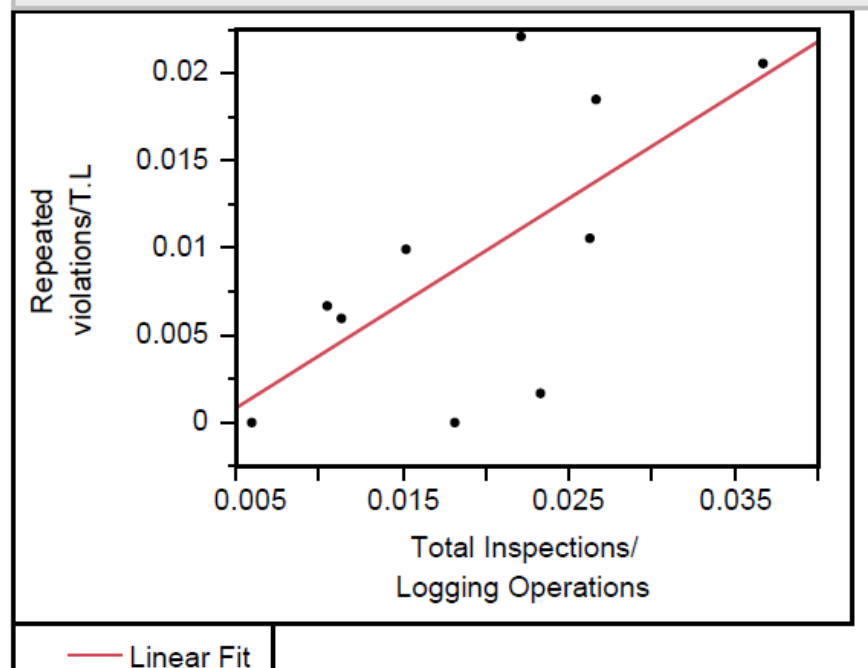

- Linear Fit

\begin{tabular}{|c|c|}
\hline \multicolumn{2}{|l|}{ Linear Fit } \\
\hline \multicolumn{2}{|c|}{$\begin{array}{l}\text { Repeated violations } / T . L=-0.002164+0.599 \\
\text { Inspections/Logging Operations }\end{array}$} \\
\hline \multicolumn{2}{|c|}{ Summary of Fit } \\
\hline RSquare & 0.439848 \\
\hline RSquare Adj & 0.369829 \\
\hline Root Mean Square Error & 0.006622 \\
\hline Mean of Response & 0.009599 \\
\hline Observations (or Sum Wgts) & 10 \\
\hline
\end{tabular}

\begin{tabular}{|c|c|c|c|c|}
\hline \multicolumn{5}{|c|}{ Analysis of Variance } \\
\hline Source & DF & $\begin{array}{l}\text { Sum of } \\
\text { Squares }\end{array}$ & Mean Square & F Ratio \\
\hline Model & 1 & 0.00027544 & 0.000275 & 6.2818 \\
\hline Error & 8 & 0.00035077 & 0.000044 & Prob > F \\
\hline C. Total & 9 & 0.00062621 & & 0.0366 * \\
\hline
\end{tabular}

\begin{tabular}{|lrrrr|}
\hline Parameter Estimates & & & & \\
\hline Term & Estimate & Std Error & t Ratio & Prob $>|t|$ \\
Intercept & -0.002164 & 0.005139 & -0.42 & 0.6848 \\
Total Inspections/Logging Operations & 0.5997312 & 0.239284 & 2.51 & 0.0366 *
\end{tabular}


Fit $Y$ by $X$ Group

Bivariate Fit of Repeated violations/T.L By Planned Inspection/Logging Operations

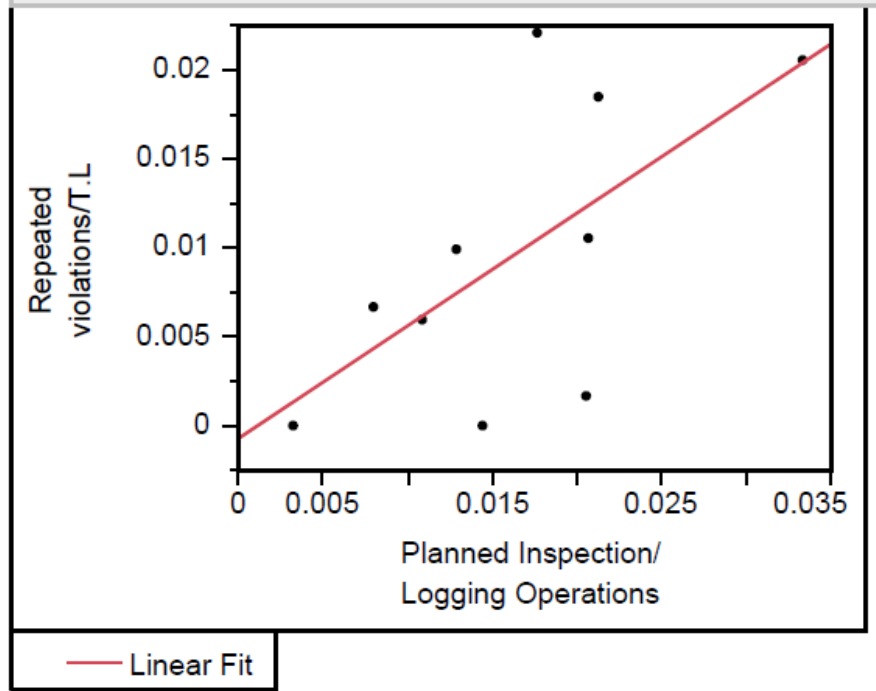

Linear Fit

Repeated violations $/ \mathrm{T} . \mathrm{L}=-0.000732+0.6345174 *$ Planned Inspection/Logging Operations

\begin{tabular}{lr}
\hline Summary of Fit & \\
\hline RSquare & 0.410105 \\
RSquare Adj & 0.336368 \\
Root Mean Square Error & 0.006795 \\
Mean of Response & 0.009599 \\
Observations (or Sum Wgts) & 10
\end{tabular}

\begin{tabular}{|c|c|c|c|c|}
\hline \multicolumn{5}{|c|}{ Analysis of Variance } \\
\hline Source & DF & $\begin{array}{r}\text { Sum of } \\
\text { Squares }\end{array}$ & Mean Square & F Ratio \\
\hline Model & 1 & 0.00025681 & 0.000257 & 5.5617 \\
\hline Error & 8 & 0.00036940 & 0.000046 & Prob $>$ F \\
\hline C. Total & 9 & 0.00062621 & & 0.0461 * \\
\hline
\end{tabular}

\begin{tabular}{|lrrrr|}
\hline Parameter Estimates & & & & \\
\hline Term & Estimate & Std Error & t Ratio & Prob $>|\mathbf{t}|$ \\
Intercept & -0.000732 & 0.004879 & -0.15 & 0.8845 \\
Planned Inspection/Logging Operations & 0.6345174 & 0.269053 & 2.36 & 0.0461 *
\end{tabular}




\section{Bivariate Fit of Certified Loggers/T.L By Loggers Trained/T.L}

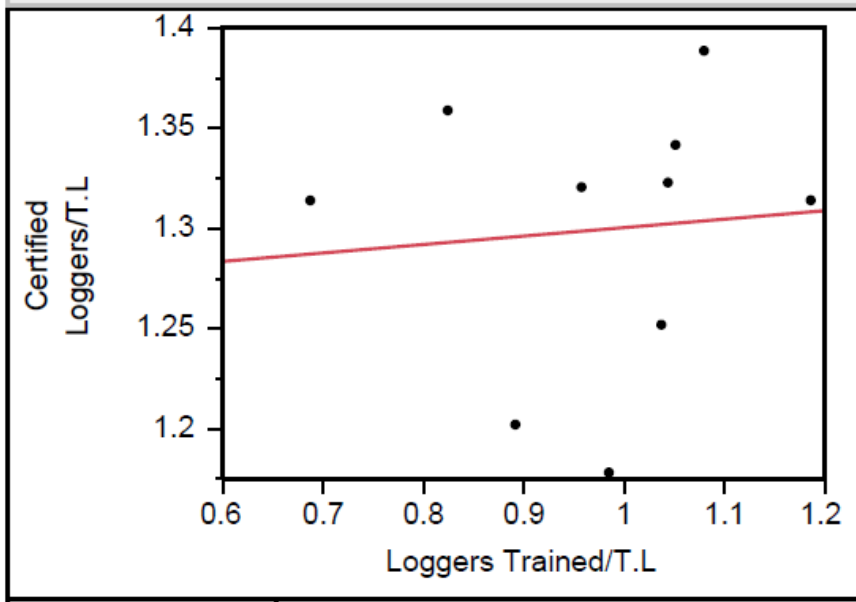

Linear Fit

Linear Fit

Certified Loggers $/ T . L=1.2582919+0.042142 *$ Loggers

Trained/T.L

\begin{tabular}{lr}
\hline Summary of Fit & \\
\hline RSquare & 0.007903 \\
RSquare Adj & -0.11611 \\
Root Mean Square Error & 0.071387 \\
Mean of Response & 1.299346 \\
Observations (or Sum Wgts) & 10
\end{tabular}

\begin{tabular}{|lr|r|r|r|}
\hline \multicolumn{4}{l}{ Analysis of Variance } \\
Source & DF & $\begin{array}{r}\text { Sum of } \\
\text { Squares }\end{array}$ & Mean Square & F Ratio \\
Model & 1 & 0.00032478 & 0.000325 & 0.0637 \\
Error & 8 & 0.04076933 & 0.005096 & Prob > F \\
C. Total & 9 & 0.04109411 & & 0.8071
\end{tabular}

\begin{tabular}{|lrrrr|}
\hline \multicolumn{4}{ll}{ Parameter Estimates } \\
\hline Term & Estimate & Std Error & t Ratio & Prob $>|\mathrm{t}|$ \\
Intercept & 1.2582919 & 0.164185 & 7.66 & $<.0001$ * \\
Loggers Trained/T.L & 0.042142 & 0.166933 & 0.25 & 0.8071
\end{tabular}




\section{Bivariate Fit of Planned Inspections By Logging Operations}

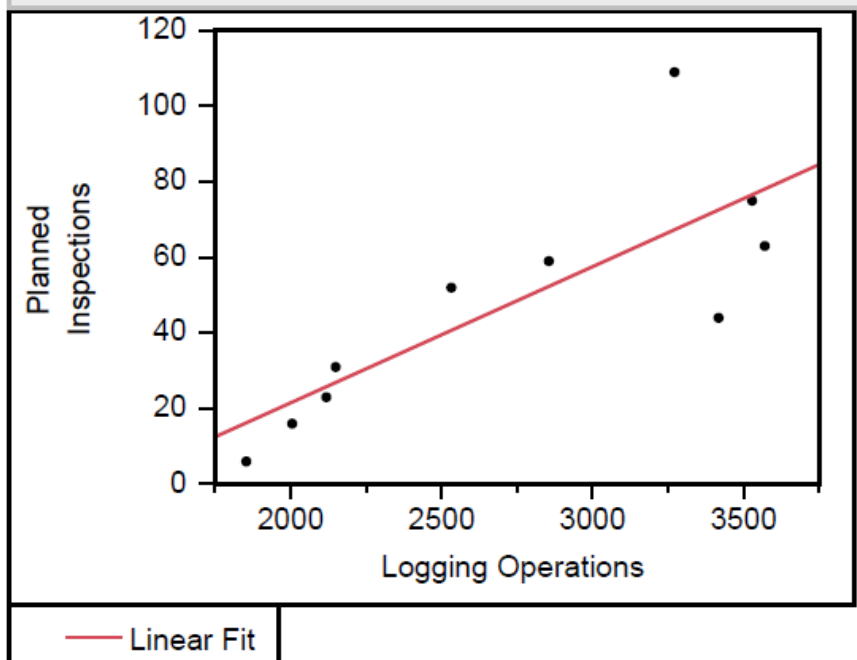

\section{Linear Fit}

Planned Inspections $=-50.55001+0.0360283^{*}$ Logging Operations

\section{Summary of Fit}

$\begin{array}{lr}\text { RSquare } & 0.6344 \\ \text { RSquare Adj } & 0.5887 \\ \text { Root Mean Square Error } & 19.74341 \\ \text { Mean of Response } & 47.8 \\ \text { Observations (or Sum Wgts) } & 10\end{array}$

\begin{tabular}{|l|r|r|r|r|}
\hline \multicolumn{5}{l}{ Analysis of Variance } \\
\hline Source & DF & $\begin{array}{r}\text { Sum of } \\
\text { Squares }\end{array}$ & Mean Square & F Ratio \\
Model & 1 & 5411.1814 & 5411.18 & 13.8819 \\
Error & 8 & 3118.4186 & 389.80 & Prob > F \\
C. Total & 9 & 8529.6000 & & 0.0058 *
\end{tabular}

\begin{tabular}{|lrrrl|}
\hline \multicolumn{4}{l}{ Parameter Estimates } \\
\hline Term & Estimate & Std Error & $\mathrm{t}$ Ratio & Prob $>|\mathrm{t}|$ \\
Intercept & -50.55001 & 27.12506 & -1.86 & 0.0994 \\
Logging Operations & 0.0360283 & 0.00967 & 3.73 & 0.0058 *
\end{tabular}




\section{Appendix F: Minitab Analysis Reports}

\section{Results for: Worksheet 6}

1. Correlations: Total Inspections/Logging Operations, Cost of Violation(Current)/T.L

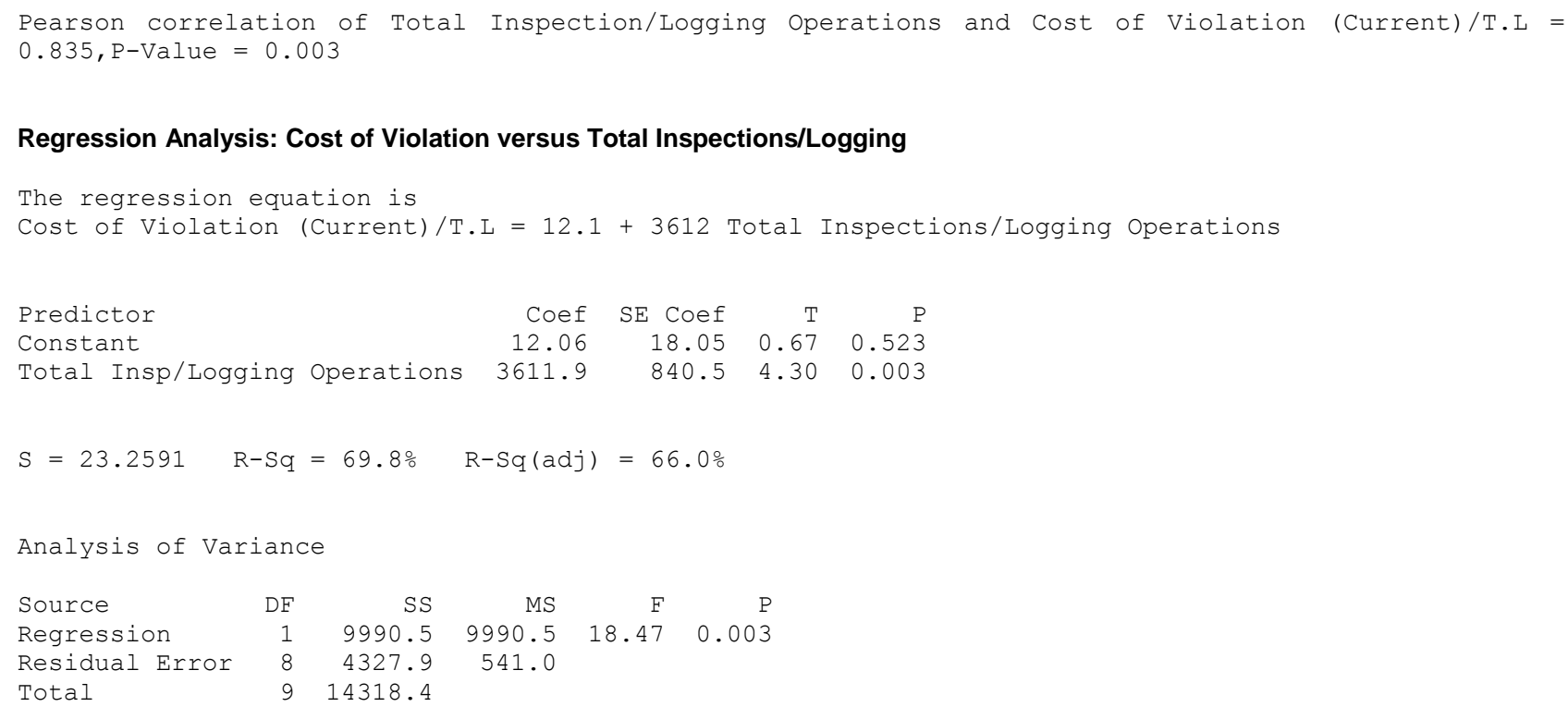

2. Correlations: Planned Inspection/Logging oper, Total Violations/T.L

Pearson correlation of Planned Inspection/Logging oper and Total Violations/T.L $=0.863, \mathrm{P}-$ Value $=0.001$

Regression Analysis: Total Violations versus Planned Inspecti

The regression equation is

Total Violations/T.L $=-0.0194+13.3$ Planned Inspection/Logging oper

$\begin{array}{lrrrr}\text { Predictor } & \text { Coef } & \text { SE Coef } & T & P \\ \text { Constant } & -0.01944 & 0.04974 & -0.39 & 0.706 \\ \text { Planned Inspection/Logging oper } & 13.259 & 2.743 & 4.83 & 0.001\end{array}$

$\mathrm{S}=0.0692708 \quad \mathrm{R}-\mathrm{Sq}=74.5 \% \quad \mathrm{R}-\mathrm{Sq}(\mathrm{adj})=71.3 \%$

Analysis of Variance

$\begin{array}{lrrrrr}\text { Source } & \text { DF } & \text { SS } & \text { MS } & \text { F } & \text { P } \\ \text { Regression } & 1 & 0.11214 & 0.11214 & 23.37 & 0.001 \\ \text { Residual Error } & 8 & 0.03839 & 0.00480 & & \\ \text { Total } & 9 & 0.15053 & & & \end{array}$

Total 90.15053

3. Correlations: Total Inspections/Logging Operations, Total Violations/T.L

Pearson correlation of Total Insp/Logging Operations and Total Violations/T.L = 0.886. P-Value $=0.001$

\section{Regression Analysis: Total Violations versus Total Insp/Loggi}

The regression equation is

Total Violations/T.L $=-0.0472+12.4$ Total Insp/Logging Operations 


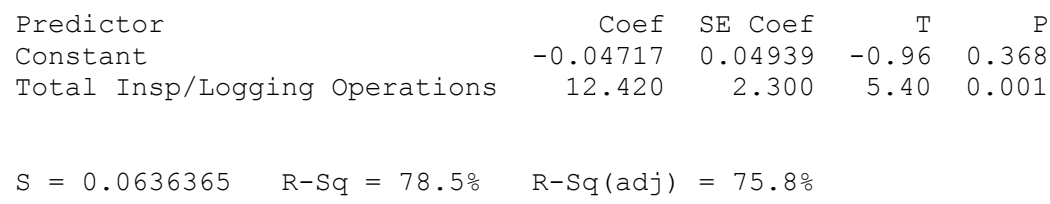

4. Correlations: Total Insp/Logging Operations, Repeated Violations/T.L Pearson correlation of Total Insp/Logging Operations and Repeated
Violations/T.L $=0.663$, P-Value $=0.037$

\section{Regression Analysis: Repeated Violations versus Total Inspections/Logging}

The regression equation is

Repeated Violations/T.L $=-0.00216+0.600$ Total Insp/Logging Operations

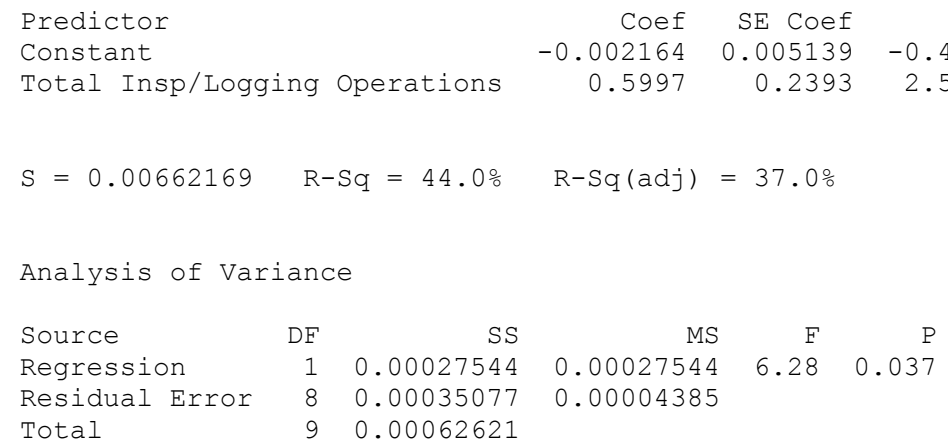

\section{Correlations: Planned Inspection/Logging oper, Repeated Violations/T.L}

Pearson correlation of Planned Inspection/Logging oper and Repeated Violations/T.L $=0.640, \mathrm{P}$-Value $=0.046$

\section{Regression Analysis: Repeated Violati versus Planned Inspecti}

The regression equation is

Repeated Violations/T.L $=-0.00073+0.635 \mathrm{Planned}$ Inspection/Logging oper

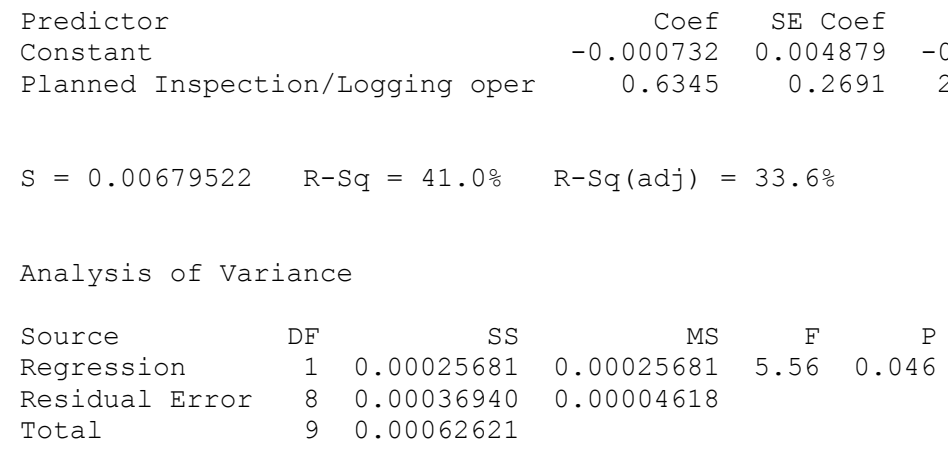

6. Correlations: Accident+Complaint Inspection_1, Planned Inspection/Logging oper 
Pearson correlation of Accident+Complaint Inspection_1 and Planned

Inspection/Logging oper $=-0.726, \mathrm{P}-$ Value $=0.0 \overline{1} 7$

\section{Regression Analysis: Accident+Complai versus Planned Inspections}

The regression equation is

Accident+Complaint Inspection_1 $1=0.208-5.97$ Planned Inspection/Logging oper

$\begin{array}{lrrrr}\text { Predictor } & \text { Coef } & \text { SE Coef } & \text { T } & \text { P } \\ \text { Constant } & 0.20792 & 0.03623 & 5.74 & 0.000 \\ \text { Planned Inspection/Logging oper } & -5.967 & 1.998 & -2.99 & 0.017\end{array}$

$\mathrm{S}=0.0504530 \quad \mathrm{R}-\mathrm{Sq}=52.7 \% \mathrm{R}-\mathrm{Sq}(\mathrm{adj})=46.8 \%$

Analysis of Variance

$\begin{array}{lrrrrr}\text { Source } & \text { DF } & \text { SS } & \text { MS } & F & P \\ \text { Regression } & 1 & 0.022711 & 0.022711 & 8.92 & 0.017 \\ \text { Residual Error } & 8 & 0.020364 & 0.002546 & & \\ \text { Total } & 9 & 0.043075 & & & \end{array}$

Total 9.043075

\section{Correlations: Accident+Complaint Inspection_1, Total Insp/Logging Operations}

Pearson correlation of Accident+Complaint Inspection_1 and Total Insp/Logging Operations $=-0.658, \mathrm{P}-$ Value $=0.039$

Regression Analysis: Accident+Complai versus Total Insp/Loggi

The regression equation is

Accident+Complaint Inspection $1=0.208-4.94$ Total Insp/Logging Operations

\begin{tabular}{|c|c|c|c|c|c|c|}
\hline Predictor & & & Coef & $\mathrm{SE} \mathrm{CO}$ & & \\
\hline Constant & & & 0.20759 & 0.042 & & 4 \\
\hline Total Insp/Logo & ing 0 & Dperations & -4.936 & & 96 & -2 \\
\hline$S=0.0552438$ & $\mathrm{R}-\mathrm{Sq}$ & $q=43.3 \%$ & $R-S q(a d j)$ & $=36$ & $.2 \%$ & \\
\hline Analysis of Var & iance & & & & & \\
\hline Source & $\mathrm{DF}$ & SS & MS & F & & $\mathrm{P}$ \\
\hline Regression & 1 & 0.018660 & 0.018660 & 6.11 & & 39 \\
\hline Residual Error & 8 & 0.024415 & 0.003052 & & & \\
\hline Total & 9 & 0.043075 & & & & \\
\hline
\end{tabular}

\section{4/28/2013 7:04:22 PM}

\section{Regression Analysis: Cost of Violatio versus Planned Inspecti}

The regression equation is

Cost of Violation(Current)/T.L $=17.4+4020$ Planned Inspection/Logging oper

$\begin{array}{lrrrr}\text { Predictor } & \text { Coef } & \text { SE Coef } & T & P \\ \text { Constant } & 17.45 & 16.07 & 1.09 & 0.309 \\ \text { Planned Inspection/Logging oper } & 4020.3 & 886.3 & 4.54 & 0.002\end{array}$

$S=22.3845 \quad R-S q=72.0 \% \quad R-S q(\operatorname{adj})=68.5 \%$ 


$\begin{array}{lrrrrr}\text { Source } & \text { DF } & \text { SS } & \text { MS } & \text { F } & \text { P } \\ \text { Regression } & 1 & 10310 & 10310 & 20.58 & 0.002 \\ \text { Residual Error } & 8 & 4009 & 501 & & \\ \text { Total } & 9 & 14318 & & & \end{array}$

\section{Results for: Minitab 2006-2010.MTW}

\section{Correlations: Medical Cost/T.L, Planned Inspection/Logging oper}

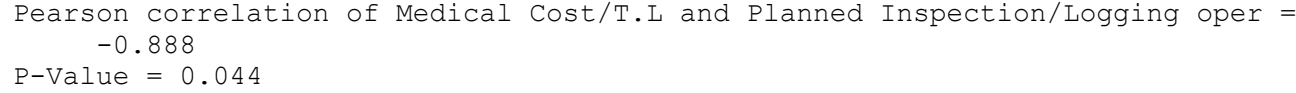

\section{Regression Analysis: Medical Cost/T.L versus Planned Inspecti}

The regression equation is

Medical Cost/T.L = 3289 - 88695 Planned Inspection/Logging oper

$\begin{array}{lrrrr}\text { Predictor } & \text { Coef } & \text { SE Coef } & \text { T } & \text { P } \\ \text { Constant } & 3289.0 & 565.7 & 5.81 & 0.010 \\ \text { Planned Inspection/Logging oper } & -88695 & 26463 & -3.35 & 0.044\end{array}$

$S=452.858 \quad R-S q=78.9 \% \quad R-S q(\operatorname{adj})=71.9 \%$

Analysis of Variance

$\begin{array}{llllll}\text { Source } & \text { DF } & \text { SS } & \text { MS } & \text { F } & \text { P }\end{array}$

$\begin{array}{lrrrrr}\text { Regression } & 1 & 2303883 & 2303883 & 11.23 & 0.044\end{array}$

Residual Error $3 \quad 615242 \quad 205081$

Total 42919125

\section{Results for: Minitab 2006-2010.MTW}

\section{Regression Analysis: Medical Cost versus Planned Insp, Loggers Trai}

The regression equation is

Medical Cost/T.L $=107$ - 98873 Planned Inspection/Logging oper + 3415 Loggers Trained/Timber Licence

$\begin{array}{lrrrr}\text { Predictor } & \text { Coef } & \text { SE Coef } & \text { T } & \text { P } \\ \text { Constant } & 107 & 1273 & 0.08 & 0.941 \\ \text { Planned Inspection/Logging oper } & -98873 & 16024 & -6.17 & 0.025 \\ \text { Loggers Trained/Timber Licence } & 3415 & 1319 & 2.59 & 0.122 \\ & & & & \\ \text { S }=265.844 \quad \text { R-Sq }=95.2 \% \quad \text { R-Sq(adj) }=90.3 \% & \end{array}$

Analysis of Variance

$\begin{array}{llllll}\text { Source } & \text { DF } & \text { SS } & \text { MS } & \text { F } & \text { P }\end{array}$

$\begin{array}{lrrrrr}\text { Regression } & 2 & 2777779 & 1388889 & 19.65 & 0.048\end{array}$

Residual Error $2 \quad 141347 \quad 70673$

Total 4291912

12. Regression Analysis: Medical Cost versus Total Insp/L, Loggers Trai

The regression equation is

Medical Cost/T.L $=-822$ - 91150 Total Insp/Logging Operations

+ 4490 Loggers Trained/Timber Licence

Predictor

Constant

Total Insp/Logging Operations

Loggers Trained/Timber Licence

$\begin{array}{rrrr}\text { Coef } & \text { SE Coef } & T & P \\ -822 & 1765 & -0.47 & 0.687 \\ -91150 & 20833 & -4.38 & 0.048 \\ 4490 & 1895 & 2.37 & 0.141\end{array}$


Analysis of Variance

$\begin{array}{lrrrrr}\text { Source } & \text { DF } & \text { SS } & \text { MS } & \text { F } & \text { P } \\ \text { Regression } & 2 & 2651225 & 1325612 & 9.90 & 0.092 \\ \text { Residual Error } & 2 & 267900 & 133950 & & \\ \text { Total } & 4 & 2919125 & & & \end{array}$

\section{Regression Analysis: Acc+ Compt In versus Planned Insp, Loggers Trai}

The regression equation is

Acc+Compt Inspection/Total Insp $=-0.256-3.73 \mathrm{Planned}$ Inspection/Logging oper +0.413 Loggers Trained/Timber Licence

$\begin{array}{lrrrr}\text { Predictor } & \text { Coef } & \text { SE Coef } & \text { T } & \text { P } \\ \text { Constant } & -0.25572 & 0.05041 & -5.07 & 0.037 \\ \text { Planned Inspection/Logging oper } & -3.7330 & 0.6346 & -5.88 & 0.028 \\ \text { Loggers Trained/Timber Licence } & 0.41288 & 0.05224 & 7.90 & 0.016\end{array}$

$\mathrm{S}=0.0105282 \quad \mathrm{R}-\mathrm{Sq}=97.5 \% \mathrm{R}-\mathrm{Sq}(\mathrm{adj})=95.1 \%$

Analysis of Variance

$\begin{array}{lrrrrr}\text { Source } & \text { DF } & \text { SS } & \text { MS } & \text { F } & \text { P } \\ \text { Regression } & 2 & 0.0087592 & 0.0043796 & 39.51 & 0.025 \\ \text { Residual Error } & 2 & 0.0002217 & 0.0001108 & & \\ \text { Total } & 4 & 0.0089809 & & & \end{array}$

Total

14. Regression Analysis: Acc+Compt In versus Total Insp/L, Loggers Trai

The regression equation is

Acc+Compt Inspection/Total Insp $=-0.290-3.40$ Total Insp/Logging Operations +0.452 Loggers Trained/Timber Licence

Predictor

Constant

Coef SE Coef $T$ P

$\begin{array}{llll}-0.29039 & 0.07493 & -3.88 & 0.061\end{array}$

Total Insp/Logging Operations $\quad \begin{array}{lllll}-3.4033 & 0.8842 & -3.85 & 0.061\end{array}$

Loggers Trained/Timber Licence $\begin{array}{lllr}0.45216 & 0.08043 & 5.62 & 0.030\end{array}$

$\mathrm{S}=0.0155335 \quad \mathrm{R}-\mathrm{Sq}=94.6 \% \mathrm{R}-\mathrm{Sq}(\operatorname{adj})=89.3 \%$

Analysis of Variance

$\begin{array}{lrrrrr}\text { Source } & \text { DF } & \text { SS } & \text { MS } & \text { F } & \text { P } \\ \text { Regression } & 2 & 0.0084983 & 0.0042491 & 17.61 & 0.054 \\ \text { Residual Error } & 2 & 0.0004826 & 0.0002413 & & \\ \text { Total } & 4 & 0.0089809 & & & \end{array}$

Total

15. Correlations: claims, medical costs

Pearson correlation of claims and medical costs $=0.953$

$\mathrm{P}-\mathrm{Value}=0.047$

\section{Regression Analysis: claims versus medical costs}

The regression equation is

claims $=-154+0.000102$ medical costs 


\section{Appendix G: OSHA Directive 2012-11(CPL 04) Logging in West Virginia}

\section{ABSTRACT}

Purpose:
References:

Cancellations:

State Impact:

Action Offices:

Originating Office:

Contact:

This notice continues a Local Emphasis Program for the Logging Industry in West Virginia.

CPL 04-00-001, Procedures for Approval of Local Emphasis Programs (LEPs); CPL 02-00-025; Scheduling System

for Programmed Inspections; CPL 02 00-150, Field Operations Manual

None.

None.

Charleston, West Virginia Area Office.

Charleston Area Office

405 Capitol Street, Suite 407

Charleston, West Virginia 25301-1727

By and Under the Authority of

Robert D. Kulick

Acting Regional Administrator

\section{LOGGING LEP}

1) Purpose. This notice continues an LEP for the Logging Industry in West Virginia.

2) Scope. This notice applies to the Charleston Area Office.

3) References. Procedures for Approval of Local Emphasis Programs (LEPs) (CPL 04-00-001); Scheduling System for Programmed Inspections (CPL 02-00-025); and the Field Operations Manual (CPL 02-00-150).

4) Expiration. This notice expires on September 30, 2012

5) Action Information.
a)
Responsible Office: Charleston Area Office
b) Action Office:
Information Office: Philadelphia Regional Office

Action. OSHA compliance personnel shall ensure that the procedures contained in this directive are followed when conducting this LEP.

7) Background. OSHA's inspection activity in logging in West Virginia has been somewhat limited in the past. Many inspections were conducted as the result of fatalities. Logging operations are often transient in nature and are not consistently active due to factors such as weather and seasonal demand for timber. The normal scheduling of programmed inspections has not typically been possible. This industry has been recognized as one of the five most hazardous industries, based on injury rates, and it is included in the OSHA Strategic Plan. Significant emphasis will be placed on this industry over the next five years to reduce its injury and illness rates. This program is designed to provide inspection coverage to logging establishments and contractors (SIC 2411) that conduct timber cutting operations in West Virginia.

8) Procedures. This LEP will be conducted throughout the State of West Virginia.

There will be two phases to the LEP, an outreach phase and an inspection phase. Each is discussed below.

Outreach Activities

1. Outreach activities will be conducted throughout FY 2012 as resources and weather permit. Charleston Area Office personnel will participate in training classes being given by the West Virginia Division of Forestry. At these sessions, CSHOs will answer questions and provide information on compliance, the LEP, and logging safety. Area Office personnel are also serving as a contact for technical and other information for the West Virginia Forestry Association, an industry group that is operating a pilot program to reduce workers compensation rates for certain of its members.

2. The Area Office will respond to queries and requests for materials generated by the letter and class participation described above.

B. Inspection Activity

1. Inspection activity will commence at the start of the fiscal year.

2. Information from neutral sources will be used to determine the location and number of logging operations in West Virginia. Neutral sources include the West Virginia Division of Forestry as well as the U.S. Forest Service.

3. The state will be divided into districts corresponding with the areas of jurisdiction of the six West Virginia Division of Forestry Districts (See Appendix A-1 Listing of West Virginia Division of Forestry as well as the U.S. Forest Service contacts and Appendix A-2 Map of Geographical Areas). These six districts will be randomly selected 
using a random numbers table (See Appendix B) to determine the order in which the districts will be planned for inspection activity. When the office is ready to conduct inspections in a particular district, the West Virginia Division of Forestry and/or the US Forestry Service will be contacted by the Supervisor/CSHO to determine the location of all of the active logging sites in that district. All of the sites will be listed on the inspection register.

4. Based on prior experience, it is estimated that it will be possible to inspect all covered logging operations in each area. It is estimated there will five to ten contractors in each district, excluding self-employed sole proprietorships, equal partnerships, and the like. The number of employers to be inspected is an estimate which may be revised during the year based on changing conditions and/or efficient use of CSHO time. If excessive numbers of loggers are found to be operating, sites to be inspected will be selected by random number table applied to the original inspection register. Sites can be inspected in any order that makes efficient use of CSHO resources.

5. Once a site has been inspected, it shall not be scheduled again for at least 6 months, unless there is a complaint, referral, or accident at the site requiring inspection.

6. Employers in SIC code 2411 may also be selected for inspection based on observation by a CSHO of a worksite at which logging is being conducted. If, in the normal course of their travels, a CSHO observes a work site within the individual area office's jurisdiction that is conducting operations in SIC code 2411, the CSHO will call the Area Office to inform the Area Director or other supervisor of his/her intent to conduct the inspection.

7. Complaints, referral and fatalities will be handled in accordance with

CPL 2.103, the FIRM

and CPL 2.115, Complaint Policies and Procedures.

8. All scheduled inspections will be comprehensive in scope and will last at

least one shift to ensure all practices, including tree felling, are observed.

IX Recording in IMIS. The IMIS identifier code to be used in item 25c on the OSHA-1 will be "LOGGING".

10) Evaluation. Not later than October 31, 2012, the Charleston Area Office will prepare a written evaluation of this LEP in the format specified by OSHA Instruction CPL 04-00-001, Appendix A. This program will be evaluated using the following activity measures and outcome measures:

A. $\quad$ Activity Measures

1. Number of inspections conducted.

2. Number, type and classification of violations per inspection.

3. Numbers of loggers attending training sessions.

4. Numbers of employees removed from risk.

B. $\quad$ Outcome Measures

1. Reduction in the numbers of fatalities.

2. Implementation of a safety and health program by at least $75 \%$ of the employers inspected.

Distribution: $\quad$ Regional and Area Offices

Regional Solicitor

Directorate of Enforcement

APPENDIX B

\begin{tabular}{|c|c|c|c|c|}
\hline I & II & III & IV & IV \\
\hline 94 & 98 & 89 & 20 & 83 \\
\hline 64 & 97 & 80 & 57 & 58 \\
\hline 18 & 33 & 15 & 65 & 41 \\
\hline 90 & 11 & 45 & 25 & 93 \\
\hline 92 & 52 & 85 & 54 & 46 \\
\hline 16 & 40 & 84 & 06 & 26 \\
\hline 74 & 75 & 49 & 71 & 87 \\
\hline 22 & 37 & 13 & 44 & 62 \\
\hline 47 & 72 & 29 & 70 & 21 \\
\hline 14 & 82 & 19 & 48 & 30 \\
\hline 100 & 63 & 08 & 78 & 34 \\
\hline 39 & 35 & 73 & 88 & 23 \\
\hline 77 & 56 & 55 & 09 & 28 \\
\hline 86 & 69 & 02 & 60 & 99 \\
\hline 51 & 79 & 32 & 43 & 07 \\
\hline 38 & 42 & 81 & 95 & 59 \\
\hline 67 & 12 & 96 & 91 & 03 \\
\hline 24 & 68 & 31 & 53 & 66 \\
\hline 01 & 61 & 27 & 17 & 36 \\
\hline 05 & 76 & 50 & 10 & 04 \\
\hline
\end{tabular}


03-R-10

Sat, 02/01/2003

Technical Release

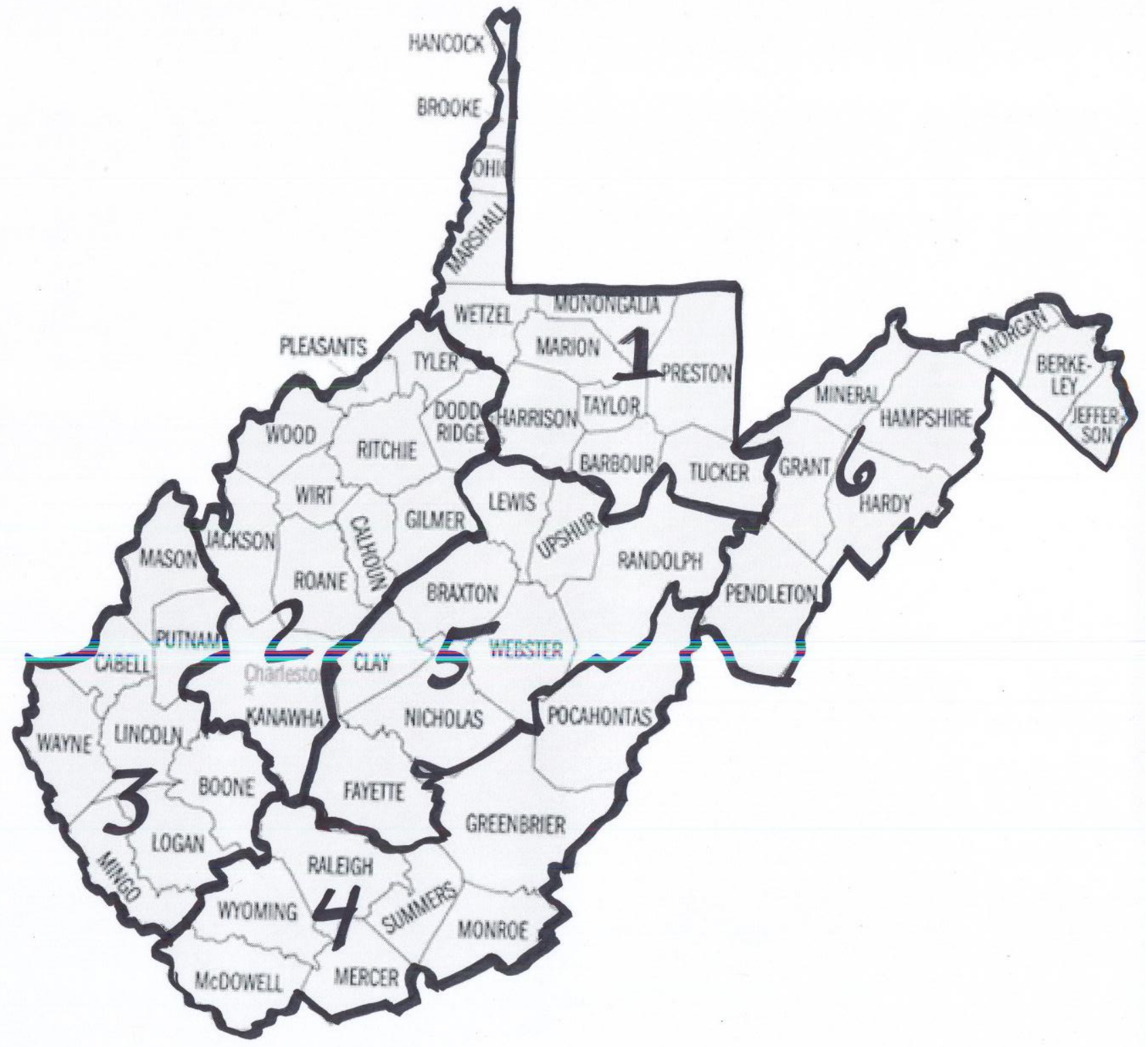

(OSHA, 2011)

LOGGING AREAS 


\section{Appendix H: Procedures for Approval of Local Emphasis Programs (LEPs).}

- Record Type:

- Directive Number:

- Old Directive Number:

- Title:

- Information Date:
Instruction

CPL 04-00-001

CPL 2-0.102A

Procedures for Approval of Local Emphasis Programs (LEPs).

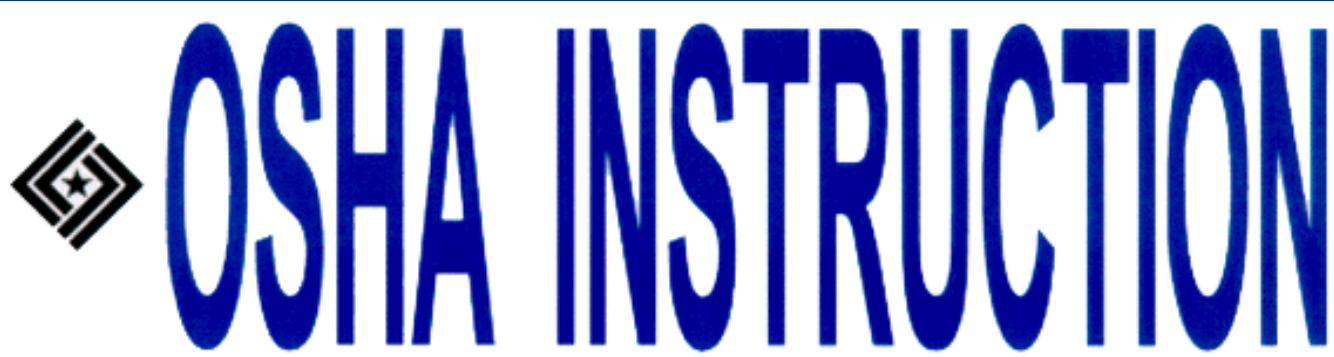

U.S. DEPARTMENT OF LABOR

Occupational Safety and Health Administration

DIRECTIVE NUMBER:CPL 2-0.102A

EFFECTIVE DATE: November 10, 1999

SUBJECT: Procedures for Approval of Local Emphasis Programs (LEPs)

\section{ABSTRACT}

Purpose:

This instruction establishes procedures for the approval of Local Emphasis Programs.

Scope:

OSHA-wide

References:

Cancellations:

State Impact:

Action Offices:

Originating Office:

Contact:
OSHA Instructions:

CPL 2.25I, Scheduling System for Programmed Inspections; CPL 2-0.51J, Exemptions and Limitations Under the Appropriations Act

CPL 2.103, the Field Inspection Reference Manual (FIRM); STP 2.22A, State Plan Policies and Procedures Manual;

OSHA Instruction CPL 2.102, March 28, 1994.

This Instruction describes a Federal Program Change for which State adoption is not required (see Paragraph VI).

National, Regional, and Area Offices

Directorate of Compliance Programs

Russelle R. McCollough

U.S. Department of Labor - OSHA

200 Constitution Ave. NW - Rm. N-3603

Washington, DC 20210 


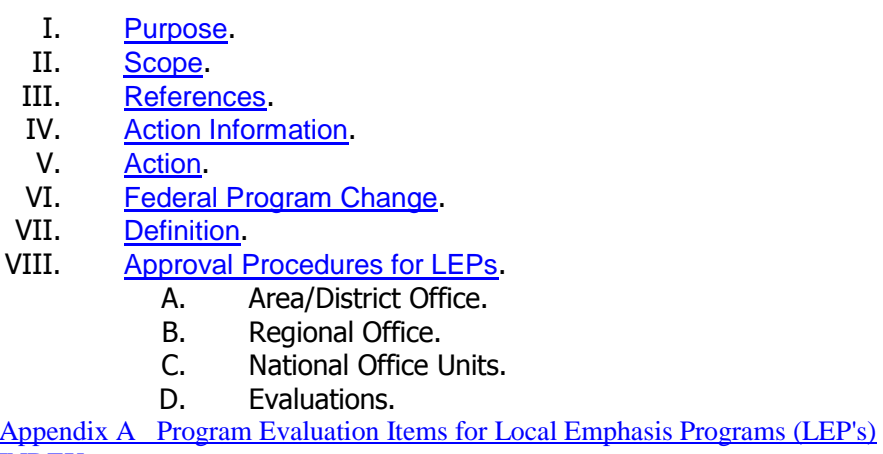

I. Purpose. This instruction establishes procedures for the approval of Local Emphasis Programs (LEPs).

II. Scope. This instruction applies OSHA-wide.

III. References.

OSHA Instruction CPL 2.103, the Field Inspection Reference Manual (FIRM), September 26, 1994

OSHA Instruction STP 2.22A CH-2, State Plan Policies and Procedures Manual, January 29, 1990:

OSHA Instruction CPL 2.25I, Scheduling System for Programmed Inspections, January 4, 1995:

OSHA Instruction CPL 2-0.51], Exemptions and Limitations Under the Appropriations Act, May 28, 1998:

IV. Action Information.

A. Responsible Office. General Industry Compliance Assistance

B. Action Offices. Regional, Area, and District Offices and State Plan States.

C. Information Offices. Consultation Project Offices.

V. Action. OSHA Regional Administrators, Area Directors, and National Office Directors will ensure that the guidelines and procedures for approval of Local Emphasis Programs set forth in this instruction are followed.

VI. Federal Program Change. This instruction describes a Federal program change for which State adoption is not required. States are asked to keep their Regional Administrators informed of State-developed local emphasis programs, experimental programs, local problem solving projects, etc., including any that relate to State Strategic Plan goals; and to coordinate with their Regional Administrator to request assignment of the appropriate IMIS identifier code.

\section{Definition.}

Local Emphasis Programs (LEPs) are a type of Special Emphasis Program, as described in OSHA Instruction CPL 2.25I, in which one or more Area Offices of a Region participate. LEPs are generally based on knowledge of local industry hazards or knowledge of local industry injury/illness experience. Whenever one or more Area Offices of a Region targets inspections to a specific industry(ies), hazard(s), or other workplace characteristic(s) -- e.g., as part of or in conjunction with a local initiative or problem-solving project-an LEP must be developed and approved. LEPs may be originated at the Area Office/District Office level, or by the Regional Office.

LEPs may include targeting of employers with 10 or fewer employees, as long as they do not conflict with restrictions under congressional Appropriations Act riders as described in OSHA Instruction CPL 2-0.51J or successor guidance. All LEPs should involve one or more of the identified hazards or the targeted industries defined in the Agency's current Strategic Plan; exceptions to this rule must be specifically authorized by the Regional Administrator.

NOTE: Programs formerly defined as "Experimental Programs" are now redefined as LEPs, with approval authority at the Regional level.

VIII. Approval Procedures for LEPs. Regional Administrators are authorized to approve LEPs with the concurrence of the Regional Office of the Solicitor of Labor (RSOL). All LEPs will involve one or more of the three hazards or the five targeted industries defined in the Agency's Strategic Plan, unless specifically authorized by the Regional Administrator. The following procedures will apply:

A. Area/District Office. LEPs may originate at the Area Office/District Office level, or by the Regional Office. Area Directors will submit their LEP request to the Regional Administrator after completing the following:

1. Developing a Regional CPL Notice (directive) for the LEP. (Notices differ from instructions in that they remain in effect no longer than one year and carry a specific cancellation date.) The notice must conform to the guidelines for directives in OSHA Instruction ADM 8.1C.

2. Ensuring that the Regional directive contains:

a. Appropriate documentation and rationale for the LEP.

b. A list of establishments or a method of generating a list of worksites from available sources; e.g., Federal, State, and local agencies, National Directory, and Local Employer Industrial Classification Manual.

c. A selection process to set forth administratively neutral criteria (e.g., random numbering system) to identify establishments for inspection. (See OSHA Instruction CPL 2.25I.)

d. An evaluation component for determining the relative success of the LEP. (See Appendix A.)

NOTE: If an LEP will target employers with 10 or fewer employees, the Regional directive must contain a statement explaining why it is appropriate for the LEP.

B. Regional Office. The Regional Administrator is authorized to approve LEPs requested by an Area Director/District Supervisor or developed by the Regional Office. When an LEP is developed by the Regional Office, the conditions outlined above at A.1. through A.2. must be met. 
The following conditions will apply to the Regional Office:

1. For new LEPs, concurrence must be obtained from the RSOL with regard to the legal sufficiency of the proposed targeting system and procedures, i.e., whether neutrality requirements for inspection scheduling are met. The RSOL may address additional issues reflecting local experience in obtaining and enforcing compulsory process. LEPs proposed for renewal must also be submitted to the RSOL for concurrence, unless the renewed LEP is identical to its predecessor. (See Appendix A of this instruction, question 5.)

2. The Regional Administrator will ensure that the LEP is assigned an IMIS identifier code for Item $25 \mathrm{c}$ of the OSHA-1 Form by the Office of Management Data Systems prior to the start of the LEP. The request will be initiated by calling the Office of Management Data Systems.

3. The approval period will be no more than one year. LEPs may be renewed year-by-year, subject to the recommendations of the LEP evaluation.

4. The Regional Administrator must provide a copy of the implementing Regional directives for all approved LEPs (including the IMIS identifier code) to the RSOL, the Directorate of Compliance Programs and the Directorate of Construction if it applies to construction.

\section{National Office Units.}

1. The Directorate of Compliance Programs/Directorate of Construction shall:

a. $\quad$ Keep copies of all LEPs and track them in all regions.

b. Provide copies of LEP documentation to the Office of Management Data Systems.

c. Provide technical assistance and advice to field offices in preparing LEP evaluation criteria and/or reports.

d. Review annual LEP evaluation reports submitted by Regional Administrators and look for possible national applications of LEPs.

e. $\quad$ Provide information on LEPs and LEP evaluation reports from other regions to Regional Administrators for their review regarding possible applications within the region.

f. Provide copies of LEPs and evaluation reports, if requested, to other Regions.

g. Provide overall direction and guidance in establishing Agency procedures for LEPs.

2. The Office of Management Data Systems will provide requested IMIS codes to Regional Administrators as soon as possible after receipt of the request.

D. Evaluations. The Regional Administrator must ensure that an evaluation of each LEP is completed and submitted to the Directorate of Compliance Programs and the Directorate of Construction (only if it applies to construction), no later than November $30^{\text {th }}$ of each year in which the LEP is active.

1. The evaluation must, at a minimum, address the LEP's role in meeting goals of OSHA's Strategic Plan, such as:

a. The number of employees covered

b. Reduction in the number of injuries and illnesses.

c. The number of workers removed from hazards.

d. Reductions in employee exposures.

e. Abatement measures implemented.

f. Number of violations related to specific targeted hazards.

2. In addition, the evaluation must respond to the questions outlined in Appendix $A$ of this instruction.

\section{Appendix A}

\section{Program Evaluation Items for}

\section{Local Emphasis Programs (LEP's)}

The program evaluations of LEPS required by this instruction shall address the following items:

16. What is the goal of the LEP? Briefly describe the purpose of the LEP (e.g., eliminate dangerous process(es), exposure to safety and health hazards, injuries/illnesses, or fatalities) and include any specifics that caused you to choose this program. How does it support OSHA's Strategic Plan?

17. In your opinion, did the LEP meet its goal?

Indicate if the program was:

* highly effective,

* effective,

* less than effective, or

* ineffective.

If this determination is not possible, indicate accordingly and briefly explain.

18. What data and information do you have to support your conclusion(s)?

At a minimum, consider the following areas of information in making your response. Note that some of the subjects listed at 3.a. through g. will not apply to every LEP. Where a subject is clearly not applicable or no responsive information can be ascertained, this should be so noted in the evaluation.

a. Enforcement statistics. Include:

* Number of inspections;

* Number of inspections in compliance;

* Number of "no inspection" cases; 
* Percent of violations cited that are serious;

* Number of employees covered by inspection;

* Dollar amount of penalties assessed;

* Percent of citations contested;

* Number of significant cases;

* Average violations per inspection; and

* Any other data which may be relevant to supporting your conclusion.

b. Significant and egregious cases:

List and briefly describe all significant and egregious cases, if any.

c. Serious hazards eliminated.

In responding, consider important:

(1) Repeat violations.

(2) Hazards cited for a given employer that do not reappear once abated, such as

hazardous airborne substances in an unventilated workplace area.

d. Evaluate and briefly comment on the overall list of standards cited to determine whether the LEP is addressing the goal.

e. Decline in occupational injuries, illnesses, and fatalities for the establishments covered by the LEP:

i. Have injuries, illnesses, and/or fatalities declined in the Region because of the program?

ii. Did the program cause a reduction of specific injuries, illnesses and/or fatalities that are common to the covered industries?

f. Impact on covered, non-inspected employers (deterrent effect on employers):

Were covered employers who were not inspected aware of the LEP, and did they eliminate serious hazards targeted by the program? If so, briefly describe significant example(s).

NOTE: Information regarding a deterrent effect might be detected from outreach sessions, new constituency groups, informal conferences, and speech and information requests.

g. Impact on suppliers of production equipment (shadow effect on suppliers):

Were manufacturers of production equipment aware of the LEP, and did they respond by modifying their products to minimize employee exposure to occupational hazards? If so, briefly describe significant example(s).

19. Should the LEP be continued?

Answer "yes" or "no" and give a brief rationale.

20. Have any legal issues arisen that should be brought to the attention of RSOL if the LEP is to be proposed for renewal? If "yes," describe them in sufficient detail for SOL to make a determination.

21. Are there any other comments or recommendations?

Consider any findings which might influence Regional or National OSHA programs and policies. Also, consider economic and technological factors impacting industries covered under the LEP, which could only be changed by revising the production process and would be beyond the employer's current financial capabilities.

(OSHA, 1999) 